\title{
Development of an Under-Sodium Ultrasonic Scanner for In-Reactor Surveillance
}

\section{Hanford Engineering Development Laboratory}

June, 1972

R. N. Ord

R. W. Smith

Physical Measurements

Measurement and Control Laboratory

\section{NOT ICE}

This report was prepared as an account of work

sponsored by the United States Government. Neither

the United States nor the United States Atomic Energy

Commission, nor any of their employees, nor any of

their contractors, subcontractors, or their employees,

makes any warranty, express or implied, or assumes any

legal liability or responsibility for the accuracy, com-

pleteness or usefulness of any information, apparatus,

product or process disclosed, or represents that its use

would not infringe privately owned rights.

This document is PUBLICLY RELEASABLE



Authorizing Gificial

Date: $\quad 1-10-07$

Contract: 


\section{DISCLAIMER}

This report was prepared as an account of work sponsored by an agency of the United States Government. Neither the United States Government nor any agency Thereof, nor any of their employees, makes any warranty, express or implied, or assumes any legal liability or responsibility for the accuracy, completeness, or usefulness of any information, apparatus, product, or process disclosed, or represents that its use would not infringe privately owned rights. Reference herein to any specific commercial product, process, or service by trade name, trademark, manufacturer, or otherwise does not necessarily constitute or imply its endorsement, recommendation, or favoring by the United States Government or any agency thereof. The views and opinions of authors expressed herein do not necessarily state or reflect those of the United States Government or any agency thereof. 


\section{DISCLAIMER}

Portions of this document may be illegible in electronic image products. Images are produced from the best available original document. 


\section{ABSTRACT}

This document describes a prototype system devised at Hanford Engineering Development Laboratory for reconstructing three-dimensional images of objects or components in liquid sodium cooled nuclear reactors. Because liquid sodium is opaque to visible light, ultrasonic scanning is used to reconstruct a pseudo three-dimensional image that can be used to observe the reactor core region for such purposes as: to identify duct assemblies; evaluating conditions of assemblies; to provide calibration backup for handling machinery accuracy and position, etc. 


\section{CONTENTS}

Page

ABSTRACT

i i i

ILLUSTRATIONS

I. INTRODUCTION 1

II. SUMMARY AND CONCLUSIONS 2

III. SYSTEM CONCEPT 3

IV. SCANNING TECHNIQUES 9

V. ISOMETRIC IMAGING IN SODIUM 11

VI. TESTING TRANSDUCERS IN SODIUM 20

VII. TRANSDUCER WETTING PROCEDURE 24

VIII. TRANSDUCER FABRICATION 27

IX. ACKNOWLEDGEMENTS 34

X. REFERENCES

APPENDIX

A-1 Isometric System Block Diagram A-1

A-2 Pulser Schematic A-2

A-3 Clock Schematic A-3

A-4 Amplifier Schematic A-4

A-5 Delay, Gate Schematic A-5

A-6 Integrator Schematic A-6

A-7 Square Wave Generator Schematic A-7

A-8 Ramp Generator Schematic A-8

A-9 Isometric Displary Generator Schematic A-9 


\section{ILLUSTRATIONS}

Page

1. Conceptual Prototype Design of U1trasonic Scanner for FFTF 5

2. Intensity Attenuation in Liquid Sodium 8

3. Under-Sodium ISO-SCAN System 10

4. Isometric System Block Diagram 12

5. U1trasnoic Scanner in Glove Box 13

6. U1trasonic Isometric Imaging of Discs 14

7. Discs with Solid Sodium After Test 15

8. U1trasonic Isometric Imaging of Nut 17

9. Ultrasonic Isometric Image of Disc (in water) 18

10. Ultrasonic Isometric Image of Disc (in sodium) 19

11. Ultrasonic Signal Reflected Off a Flat Stainless Steel Target in $490^{\circ} \mathrm{F}$ Sodium 23

12. Temperature Effects of Sodium Wetting on Various Materials 26

13. Under-Sodium Viewing Transducer Assembly - USV Series 28

14. Photos of Transducer Assemblies 30

15. Thermal Etching/Deposition Assembly 32

16. Bonding Assembly 33

$\underline{\text { TABLES }}$

I. In-Sodium Testing of USV Transducers (Series "A") 


\section{INTRODUCTION}

Visual observation in 1 iquid sodium cooled nuclear reactors cannot be achieved because of coolant opacity to visible light. The problem of opacity can be overcome by the in-vessel use of an ultrasonic scanning system having the capability of reconstructing three-dimensional images of the components or objects being scanned by a beam of ultrasonic energy. This report describes the progress achieved to date toward development of a prototypic scanning system to be built for the Fast Flux Test Facility (FFTF). Initial tests will be done in the High Temperature Sodium Facility at the Hanford Engineering Development Laboratory.

The under-sodium scanner will be designed for insertion into the FFTF during shutdown when sodium temperature will range between 400 and 500 o . The scanner could be used to:

- Visually observe the core region to insure that handling machinery and other moving mechanisms can be maneuvered properly.

- Determine the elevation profile of the fuel duct assemblies.

- Identify each duct assembly.

- Determine the operability of the fuel handling machine, including the grapple mechanism.

- Evaluate the condition of the duct assembly handling sockets.

- Evaluate the condition of the instrument tree mechanisms.

- Check the operability and condition of the core restraint arms and jaws, if accessible.

- Provide calibration backup for determining handling machinery accuracy and position.

- Visualize azimuthal motion of the duct assemblies on release or on application of the core restraint system. 


\section{SUMMARY AND CONCLUSIONS}

This report describes the significant accomplishments for the program to date, including the developments leading toward the prototypic scanner system for the FFTF and for future LMFBRs. The two key accomplishments developed thus far have been: (1) the development of the three-dimensional isometric image construction process (termed ISO-SCAN) to aid in visualizing the in-sodium reactor components; and (2) a technique to wet the ultrasonic transducer faceplate in 400 to $500^{\circ} \mathrm{F}$ sodium. These accomplishments open the way to the design of a scanning system meeting the requirements of the FFTF.

The time involved to scan an object can be greatly reduced by mounting the transducer on a rotating scanning head. The spatial coordinates of the rotating scanning head and the time of flight of the ultrasonic pulse reflected from the object being scanned are used to construct the ISO-SCAN image on a memory display screen. This beneficial technique has more complexity than does the conventional C-scan method of ultrasonics; however, it is far less complex than the process required for holographic imaging.

U1trasonic imaging at sodium temperatures in the 400 to $500^{\circ} \mathrm{F}$ range requires certain precautions to insure proper wetting of the transducer face plate in liquid sodium to achieve maximum signals. Also, wetting of the target surfaces must be assured. Thus far, scanning has been performed in an open sodium vessel in an argon-filled glove box. The sodium acts as a good "getter" for the small quantity of oxygen in the argon and therefore inhibits the wetting process at these temperatures. To overcome this problem, a sealed scanning tank, now designed and fabricated, will be used for planned testing starting in FY-1973. The sodium will flow through the tank and be purified on a routine basis. The results of these tests should provide realistic parameters for the design of the prototypic scanner for FFTF.

Access availability for the FFTF places stringent design constraints on the size and shape of the mechanical scanning head and arm assembly. Several 
8.5-in. diameter entrance ports above the core region of the reactor will be available for possible insertion of the planned telescoping scanning arm.

Clever mechanical design will be required to reduce vibration to an acceptable level for the scanning accuracies desired (resolution of two 10-mil diameter holes $10 \mathrm{mils}$ apart using a 2-in. focal length ultrasonic transducer). The design, construction and tests of the prototypic scanner in CRCTA will be done prior to constructing the final scanner for use in FFTF during shutdown conditions.

\section{SYSTEM CONCEPT}

Ultrasonic viewing in opaque liquid sodium in the FFTF requires the development of an accurate scanning system. The background development for the system concept and the design constraints will be explained in this section of the report.

For those not familiar with ultrasonic principles, the physical laws governing sound propagation relate closely to those used for electromagnetic waves. The fundamental concept involves the coupling of sound energy from a generator (transducer) into and out of the liquid sodium. Sound waves can be generated using a piezoelectric element which converts electrical energy into mechanical motion and vice versa. A metallic lens serves to focus the sound energy and direct it toward the target. For a transducer face oriented to beam energy to the target surface, a reflected sound pulse will be received by the transducer. Then, knowing the propagation velocity of the sound wave in sodium and the spatial coordinates of the transducer as it moves near the target in a prescribed manner, a three-dimensional image (termed ISO-SCAN) can be "constructed" for display on a memory-type cathode ray tube (CRT).

The amount of target area being scanned by the transducer during any given time period can be increased by use of a rotating scanning head having 
several transducers. The head will rotate at speeds up to a few hundred rpm and translate the transducer energy beam nearly perpendicular to the object surface. Determination of the actual scanning motion of the rotating head for use in FFTF will be based on the particular targets of interest. Thus, this determination will stipulate the number of rotational and translational degrees of freedom needed for the scanner, while falling within the access constraints of the reactor vessel.

For the prototypic system, present planning involves an L-shaped scanning arm, with the transducer head rotating on the end of a telescoping arm. The assembly would be driven from above by motors through a gear train shown in Figure 1, a conceptual drawing. Several side- and down-viewing transducers having short focal length lenses for high resolution (a few mils) and long focal lengths for distant viewing, will be incorporated into the rotating head assembly. A general mapping of the entire region of interest would precede the scanning of specific components and objects. The sideviewing mapping would thus insure that no obstacles would prevent the close viewing by the short focal length transducers.

The scanning motion of the rotating transducer head will follow a mathematical function to fit the geometric contour of the reactor access region. For instance, a sinusodial function with an increasing amplitude toward the outer boundary of the FFTF vessel may be optimum. The rotation of the head must be synchronized with the translational motion to create a uniform scan pattern. The control electronics will have limit switches, span settings, rotation speed controls, and ultrasonic signal gain and gate adjustments. The ultrasonic signal reflected from the target surface will be multiplexed with the position coordinates of the transducer head and the angle increments from an optical encoder. This information will be placed in the memory unit of a smal1 computer where the data wi11 be operated on to form the image coordinates for the CRT memory screen.

Various image orientation adjustment angles will be possible using the control module switches to change the image in real time using the coordinate 



No. $7207-18.3$

Figure 1. Conceptual Prototype Design of UItrasonic Scanner for FFTF. 
information stored in the computer memory. Equations for a general image rotation using Eulerian angles are given below; the $X, Y$ and $Z$ axes attach to the "object":

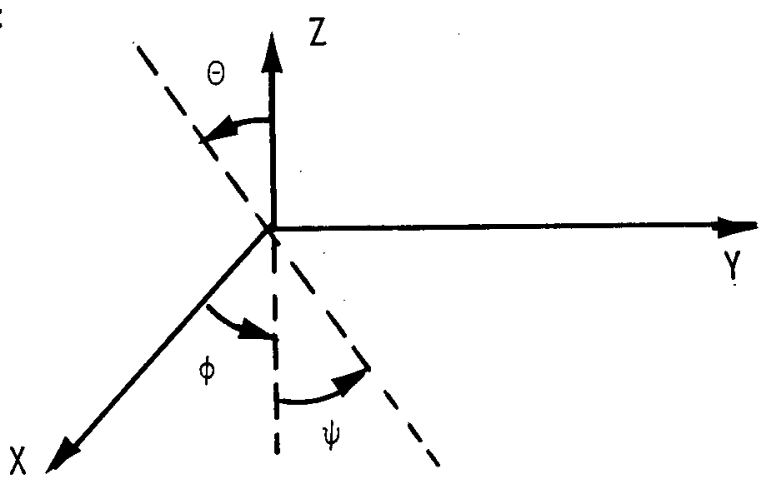

Rotation will take place in this order:

$\phi$ - rotate about the $Z$ axis

$\theta$ - rotate about the new $X$ axis

$\Psi$ - rotate about the new $Z$ axis

The image axis coordinates $X^{\prime}, Y^{\prime}$ on the memory screen result from the following transformation:

$$
\left[\begin{array}{l}
X^{\prime} \\
Y^{\prime} \\
-
\end{array}\right]=\left[\begin{array}{ccc}
\cos \Phi & \sin \Phi \cos \theta & \sin \Phi \sin \theta \\
\sin \Phi & \cos \Phi \cos \theta & \cos \Phi \cos \theta \\
0 & -\sin \theta & \cos \theta
\end{array}\right]\left[\begin{array}{ccc}
\cos \Psi & \sin \Psi & 0 \\
-\sin \Psi & \cos \Psi & 0 \\
0 & 0 & 1
\end{array}\right]\left[\begin{array}{l}
x \\
y \\
z
\end{array}\right]
$$

The final equations result from multiplication of the matrices:

$$
\begin{aligned}
X^{\prime}= & X[\cos \Phi \cos \psi-\sin \Phi \cos \theta \sin \psi]+Y[\cos \Phi \sin \psi+\sin \Phi \cos \theta \cos \psi] \\
& +Z[\sin \Phi \sin \theta] \\
Y^{\prime}=\quad & X[-\sin \Phi \cos \psi-\cos \Phi \cos \theta \sin \psi]+Y[-\sin \Phi \sin \psi+\cos \Phi \cos \theta \cos \psi] \\
& +Z[\cos \Phi \sin \theta]
\end{aligned}
$$


Several ultrasonic equations will be of interest regarding the sizes necessary for system design. The wave length, $\lambda$, for sound traveling in liquid sodium with frequency $f \cong 5 \mathrm{MHz}$ will be:

where,

$$
\lambda=\frac{V}{f}=0.0192 \text { inches, }
$$

$$
V=0.96 \times 10^{5} \text { inches/second in liquid sodium at } 500^{\circ} \mathrm{F} \text {. The far- }
$$

field distance, $N$, for a usable imaging signal (assuming a piston driver source), can be obtained from the following approximate equation:

$$
N=\frac{D^{2}}{4 \lambda}=\frac{(0.5)^{2}}{4(0.0192)}=3.255 \text { inches, }
$$

where we have assumed a transducer diameter $D=0.5$ inches and frequency $f=$ $5 \mathrm{MHz}$. The above equation will be valid when $\lambda \ll D$.

The beam spread in the far field due to the diffraction of a circular source and single frequency can be obtained as follows:

$$
\sin \gamma=\frac{1.22 \lambda}{D}=\frac{1.22(0.0192)}{0.5}=0.046
$$

The resolution distance between two sound-emitting point sources (ignoring secondary effects) can be obtained using the Rayleigh criteria:

$$
a=x \sin \gamma
$$

where $X$ is the distance from the source to the focal plane, i.e., the focal distance.

Figure 2 shows the attenuation of the sound wave in liquid sodium. The curves show relative intensity versus distance from the acoustic source for several sound frequencies. Note that the sound intensity reduces by about $50 \%$ for 24 inches (one way) of travel using $5 \mathrm{MHz}$ ultrasonic frequency. 




Figure 2. Intensity Attenuation in Liquid Sodium 


\section{SCANNING TECHNIQUES}

Several scanning concepts have been suggested as possible candidates for in-vessel inspection in liquid sodium. The British (1) describe a potential concept for use during reactor operation where temperatures $\left(400\right.$ to $600^{\circ} \mathrm{C}$ ) preclude using conventional ultrasonic transducers immersed in liquid sodium. Their design couples an ex-vessel piezoelectric transducer with a solid or liquid waveguide which then transmits the sound energy into the appropriate region above the core of the reactor. A rotating mirror reflects the sound energy across the region to be inspected; thus, objects can be located by means of their intrusion into the sound beam. The major difficulty associated with this concept results from the coupling of sound energy into and out of the waveguide and from the limited use of the scanner mechanism.

Scott and Ying, working for Atomic Power Development Associates, reported on the "Development of the Under-Sodium U1trasonic Scanner"(2) in 1967. They were able to experimentally image several targets in liquid sodium using conventional ultrasonic " $C$ " scan techniques over a temperature range of 300 to $600^{\circ} \mathrm{F}$. They reported good resolution of objects $1 / 32$ inch wide and $1 / 16$ inch deep.

For the FFTF, inspection will be involved only during reactor shutdown at temperatures less than $500^{\circ} \mathrm{F}$, thus, the ultrasonic transducer can be placed directly in the liquid sodium. The transducer will be used both as a transmitter and a receiver; it will be moved to scan the target and thus enable creation of the isometric image discussed in the system concept of this report.

The images presented in this report were obtained using a rectilinear scanning system illustrated in Figure 3. The ultrasonic transducer, when immersed in a vessel of liquid sodium, translates in the horizontal plane using digital stepping motors. Preset indexers control the speed, direction and length of span of the moving transducer. Electric signals from the 


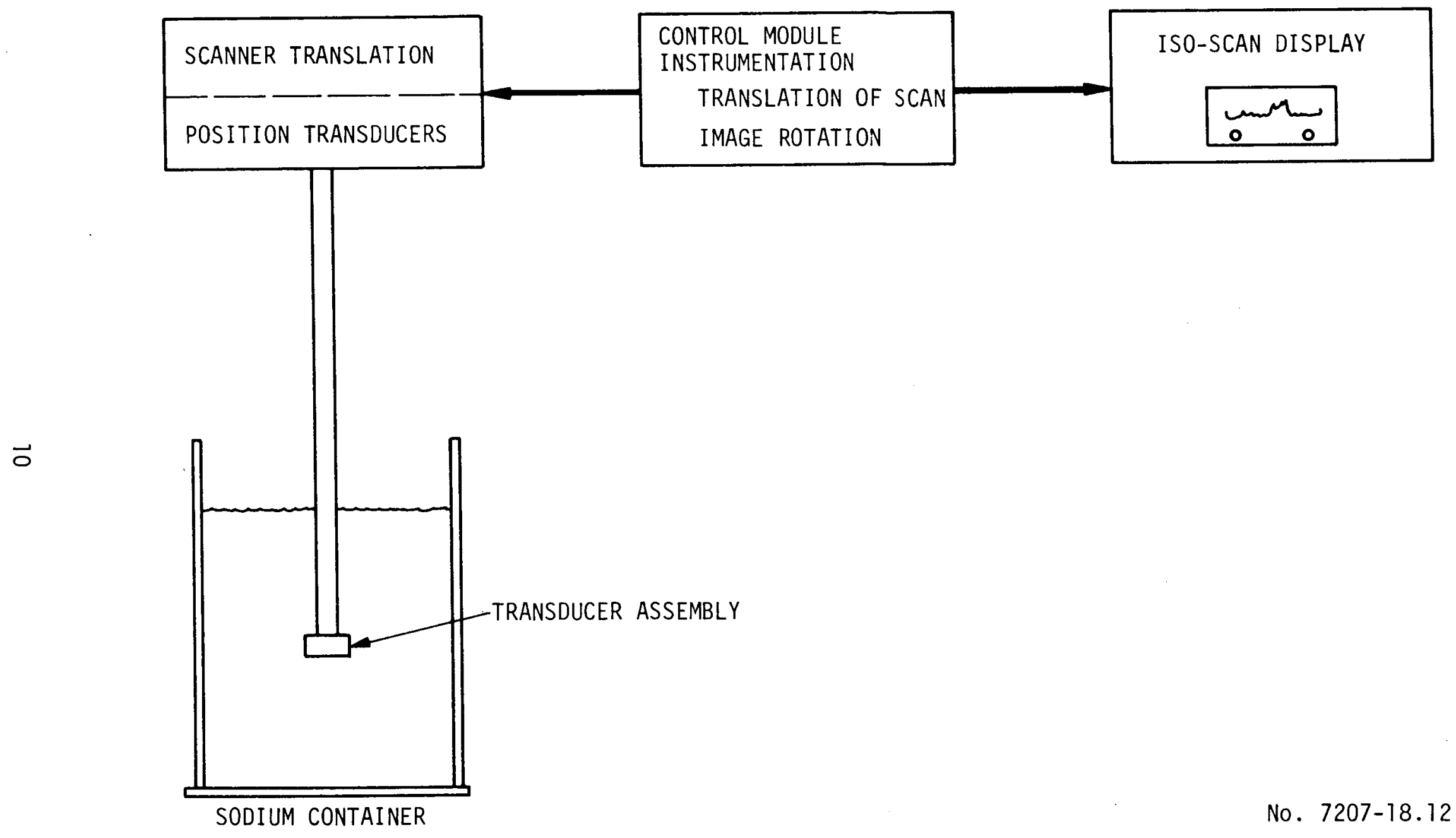

Figure 3. Under-Sodium ISO-SCAN System 
transducer and the position sensors are combined, as shown in Figure 4 , to produce an image on a storage display screen (CRT). Appendix A gives the detailed schematics of the electronic circuits.

\section{ISOMETRIC IMAGING IN SODIUM}

The initial ultrasonic scanning experiments in liquid sodium were performed in a sodium pot located in an argon-filled glove box in the Hanford Engineering Development Laboratory 324 Building. Figure 5 shows the scanner and the open vessel of sodium inside the glove box. The object being scanned by the ultrasonic transducer rests on the bottom of the sodium vessel. Although the sodium contained less than $5 \mathrm{ppm}$ oxygen after vessel filling, the hot sodium continually absorbed oxygen from the argon cover gas. This appears to be reason for the $\mathrm{film}$ seen on the surface of the liquid sodium.

Figure 6 shows an isometric image of several 0.25-in. thick discs placed on top of each other. A comparison of the sodium scan with the previous scan in water shows the effect of sodium non-wetting of the objects. Figure 7 shows this effect quite clearly; solid sodium can be seen on the discs after removal from the sodium vessel. The curved effect at the edges and void regions can be correlated with the ISO-SCAN image. This non-wetting condition should not occur for objects previously heated to $800^{\circ} \mathrm{F}$ or exposures at a lower temperature for a longer period of time. The section of this report on transducer wetting expands on this particular subject.

The three-dimensional isometric scanning technique (ISO-SCAN) has been reported in an invention disclosure by Becker and Trantow(3). Essentially, this technique creates the third dimension by adding the time of flight of the ultrasonic pulse to the $X, Y$ coordinates of the transducer as it scans the object. Electronic manipulation of these signals enables the generation of the perspective of the image. In scanning, the transducer will direct the energy beam perpendicularly to the top surfaces of the object, but the image can be rotated electronically to gain the desired perspective of the object 


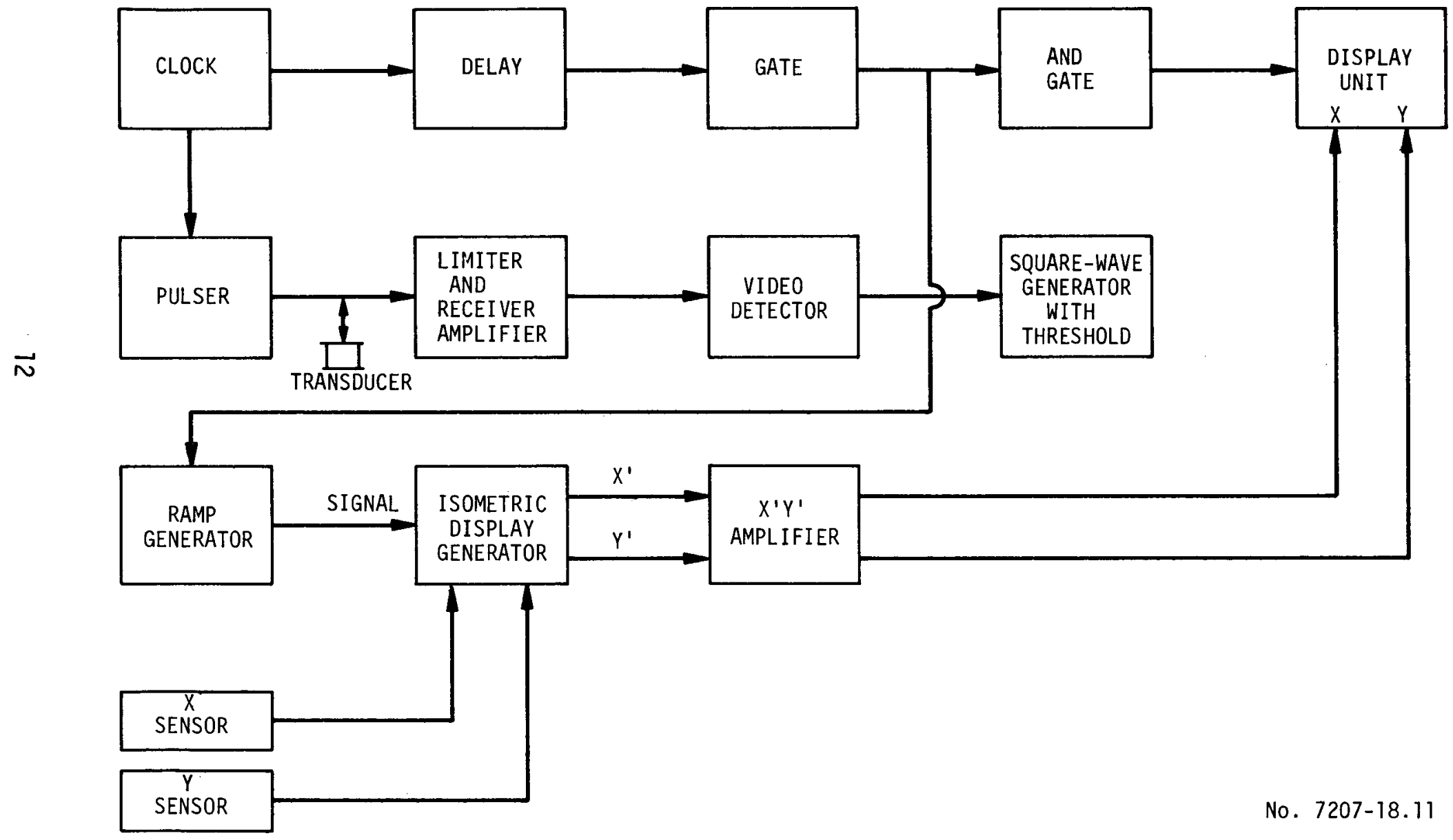

Figure 4. Isometric System Block Diagram 




$721765-5$

Figure 5. Ultrasonic Scanner in Glove Box 


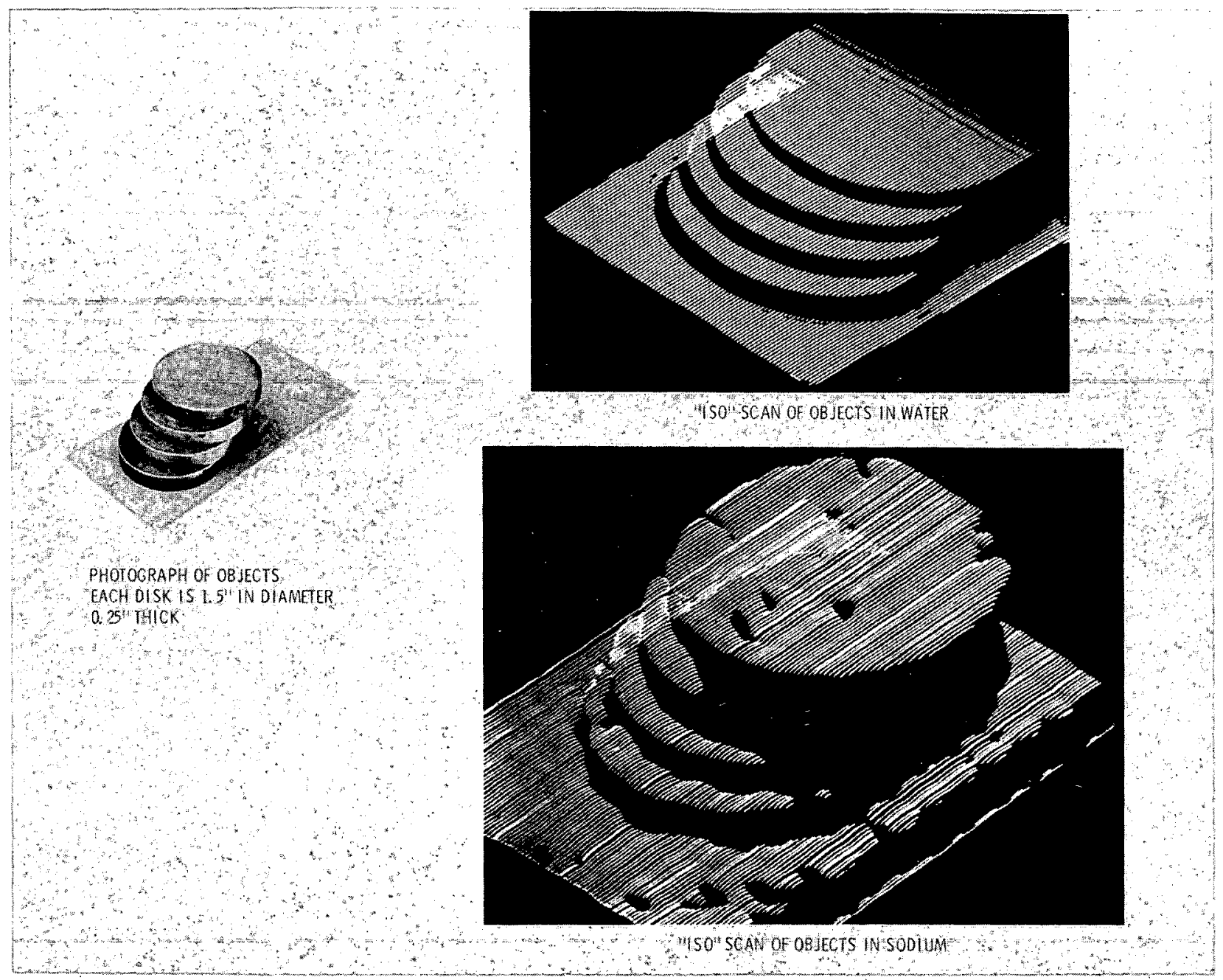

Figure 6. Ultrasonic Isometric Imaging of Discs 


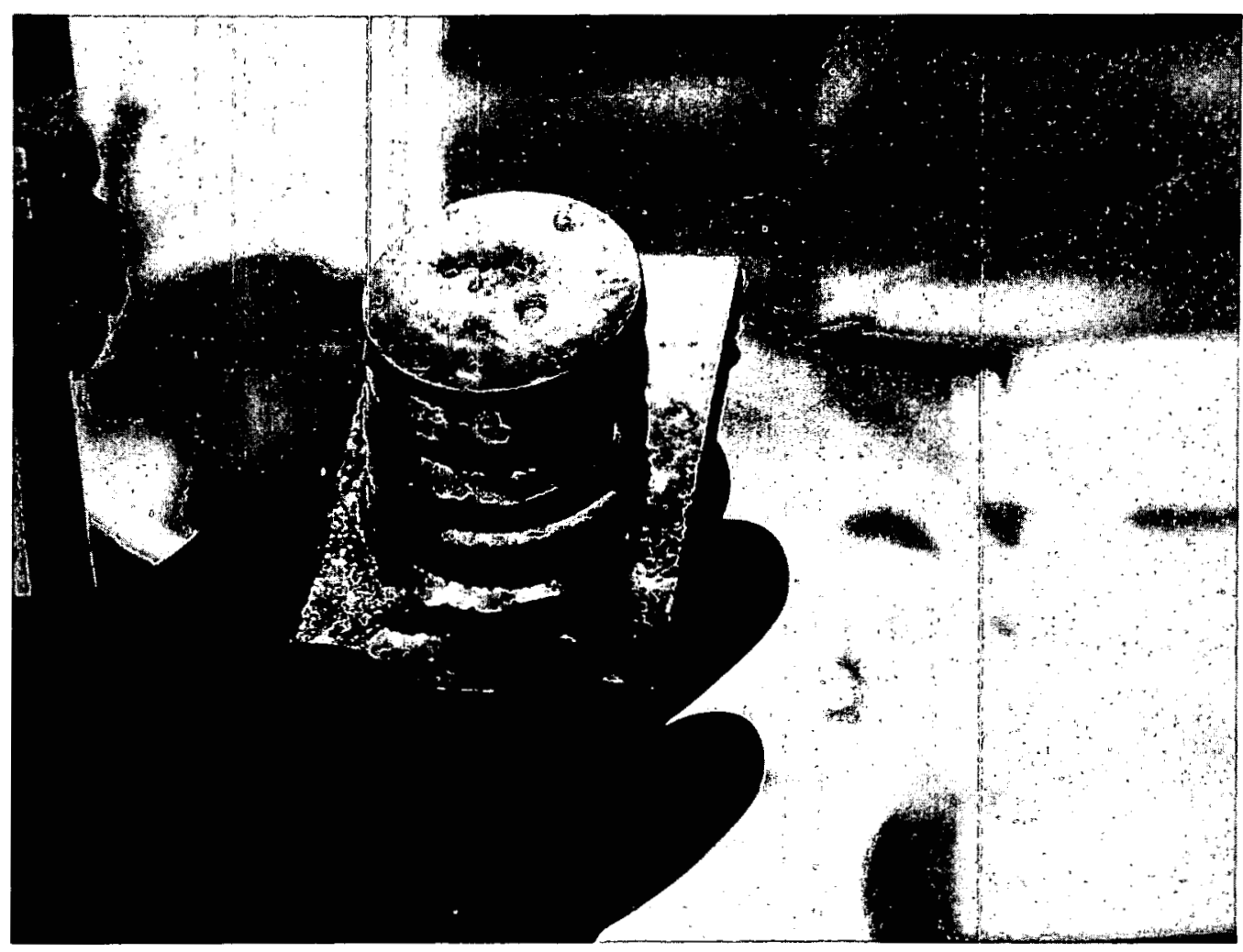

721762-7

Figure 7. Discs with Solid Sodium After Test 
for display.

Figure 8 shows an isometric image of a nut having a 7/8-in. inside diameter. Notice that the tapered edges can be seen both in the water scan and in the sodium scan, although the edges are not perpendicular to the transducer beam. Removal of the nut from the liquid sodium revealed a non-wetted surface, whereas the bottom of the tank indicated partial wetting. In explanation, these results stem from one or two possibilities: (1) heaters were used to heat the bottom of the tank; and/or (2) the ultrasonic signal might have been closer to the "noise level" due to the transducer being focused nearer the top surface of the nut, thereby introducing scan uncertainty into the signal information used to "write" the image on the cathode ray screen. The largest reflected ultrasonic signal would be obtained from a totally non-wetted surface, rather than a wetted surface, since part of the sound energy will be absorbed by a wet surface. In the FFTF, all surfaces should be wet; thus, about $83 \%$ of the energy should be reflected back to the transducer.

Figures 9 and 10 show in-water and in-sodium scans of a stainless steel disc having engraved letters. Again, in the case of the sodium scan, some lack of wetting occurred, thereby reducing the quality of the scan. In Figure 10, the "zero" on the left hand side resulted from a drop of sodium splashing on the cold disc. 

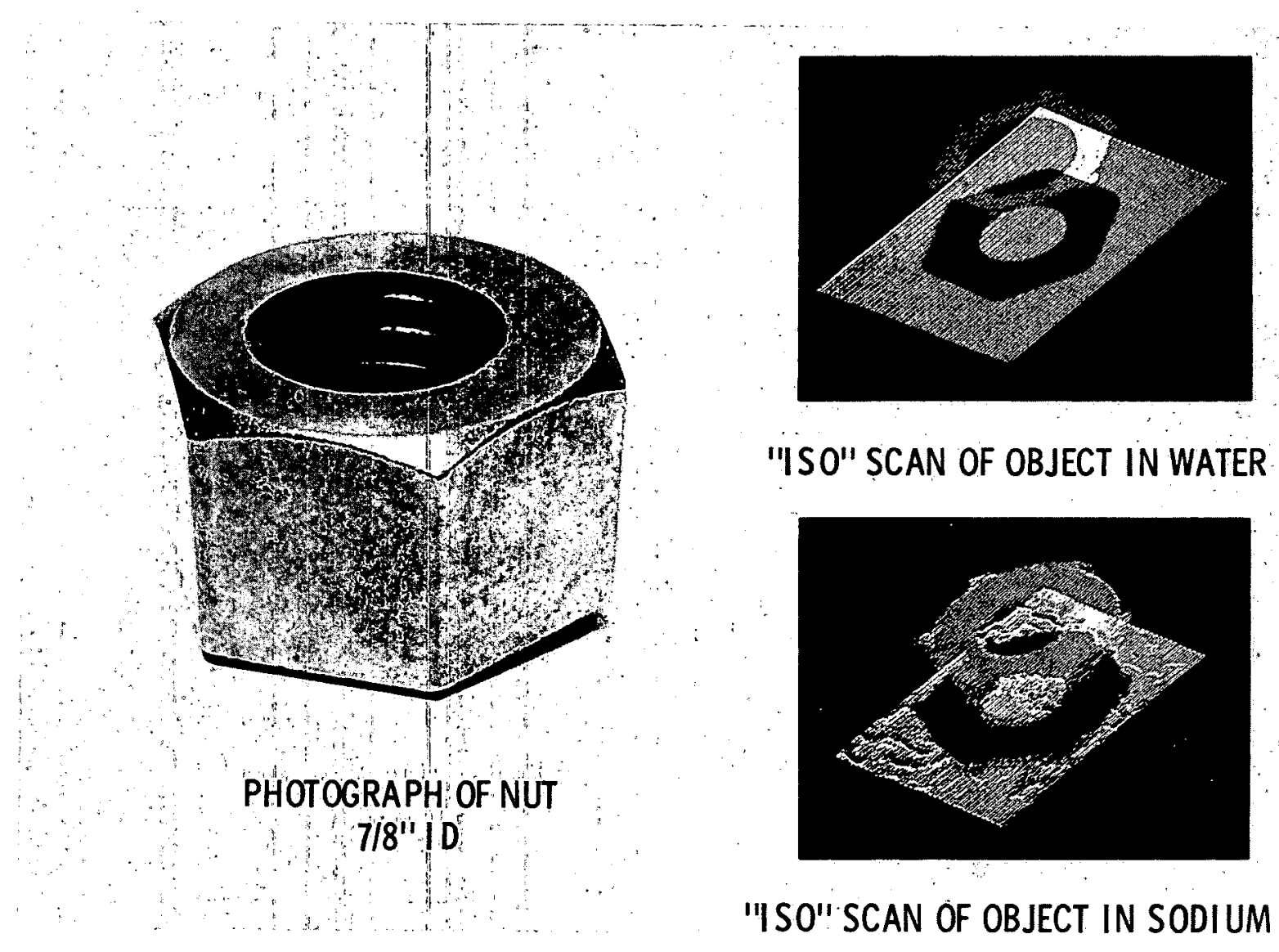

Figure 8. UTtrasonic Isometric Imaging of Nut

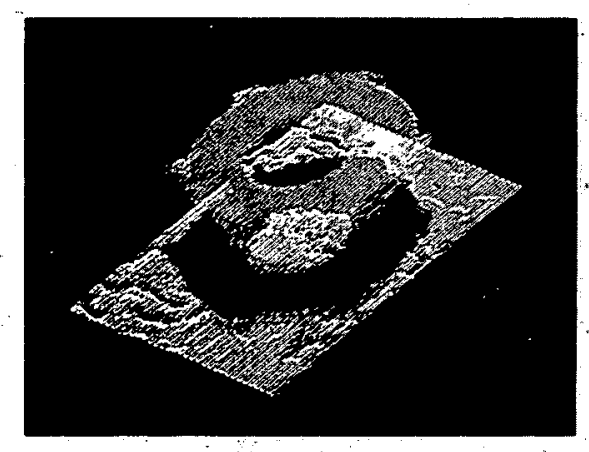

"ISO" SCAN OF OBJECT IN SODIUM

$721762-3$ 


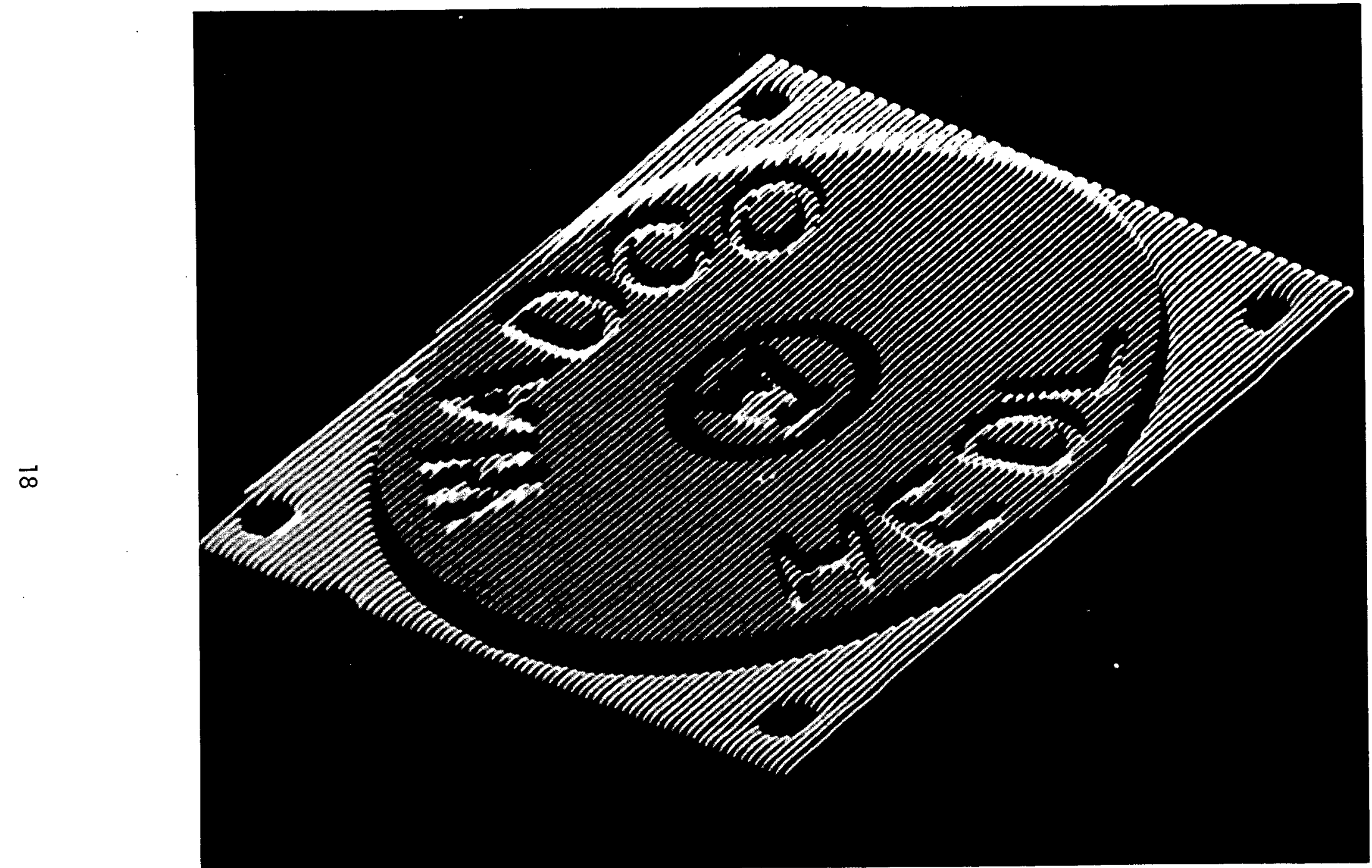

$721762-1$

Figure 9. Ultrasonic Isometric Imaging of Disc (in water) 


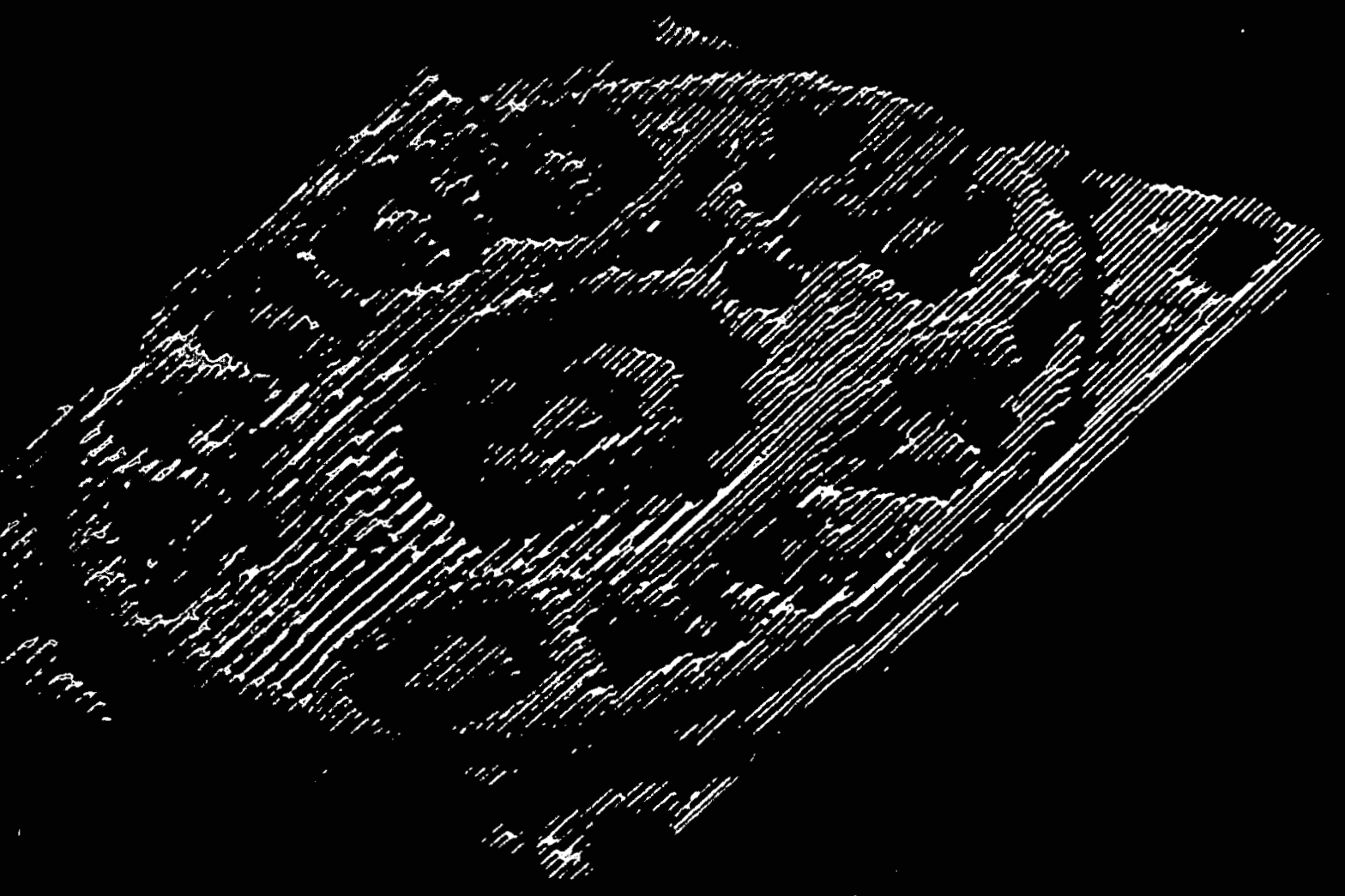

Figure 10. Ultrasonic Image of Disc (in sodium) 


\section{TESTING TRANSDUCERS IN SODIUM}

Eighteen in-sodium transducer experiments have been completed in FY-1972. Nine long-term tests in flowing, reactor-grade sodium were conducted. Two tests lasted for approximately 300 hours, with the sodium temperature varying from $460^{\circ} \mathrm{F}$ to $490^{\circ} \mathrm{F}$. At the conclusion of these experiments, the transducers (a11 PZT or lead-zirconate-titanate) operated satisfactorily: they had retained approximately $50 \%$ of their initial pulse-echo sensitivity. Two additional tests lasted for 160 hours and 650 hours, respectively, at sodium temperatures ranging from $460^{\circ} \mathrm{F}$ to $490^{\circ} \mathrm{F}$. These transducers showed no loss in sensitivity; at the conclusion of the tests, they were operating satisfactorily.

In addition to the described early experiments, five other transducers (Series A) were tested on a long-term basis to establish transducer reliability and to obtain more quantitative results about transducer wetting. Earlier results proved to be somewhat qualitative in nature, because the transducers were not identical, and transducer alignment in the test fixture affected the measurements of sensitivity. For the later experiments, the five transducers (see Transducer Fabrication) were fabricated to be as identical as possible. The experiments lasted for a minimum of 120 hours each in flowing, reactorgrade $\left(<5 \mathrm{ppm} \mathrm{O}_{2}\right)$ sodium at temperatures ranging from $470^{\circ} \mathrm{F}$ to $500^{\circ} \mathrm{F}$. Measurements of the transducer pulse-echo sensitivity in water preceded the sodium tests to enable direct comparison of performance. The in-sodium sensitivity measurements took place at various intervals throughout the tests.

Table I shows the results of these experiments in flowing sodium, in which all transducers wet reasonably we11. The in-sodium sensitivity (referred to the water pulse-echo sensitivity) varied from $16 \%$ to $37 \%$, indicating that the degree of wetting varied considerably from unit to unit. A11 units underwent tests for more than 120 hours. For a 11 but USV-17 and USV-24, no substantial change in sensitivity occurred throughout the experiments. The sensitivity of No. 17 increased from $26 \%$ initially to $37 \%$ at test termination. 
Later, we determined that the active element in USV-17 had cracked after removal from the loop. Transducer USV-24 cracked after two days of testing due to thermal shock associated with a malfunction of the sodium loop; the malfunction caused a three-day shutdown. Testing after startup continued; however, the transducer sensitivity had reduced to about 19\%, as compared to $35 \%$ noted during the initial two days of testing. The sensitivity remained at the $19 \%$ level.

TABLE I

IN-SODIUM TESTING OF USV TRANSDUCERS -- SERIES "A"

\begin{tabular}{|c|c|c|c|c|}
\hline \multirow{2}{*}{ Transducer No. } & \multicolumn{2}{|c|}{ Pulse-Echo Sensitivity***(Peak-To-Peak Volts) } & $\begin{array}{c}\text { Test } \\
\text { Duration } \\
\text { (hr) }\end{array}$ \\
\cline { 2 - 5 } & Water & $\begin{array}{l}\text { Flowing } \\
\text { Sodium }\end{array}$ & $\%$ of Water Sensitivity & 139 \\
20 & 3.5 & 1.3 & $37 \%$ & 163 \\
21 & 8.0 & 1.3 & $16 \%$ & 241 \\
22 & 6.2 & 1.5 & $24 \%$ & 122 \\
$24 * \star$ & 5.0 & 1.3 & $26 \%$ & 120 \\
\hline
\end{tabular}

* For No. 17, the sensitivity varied from $26 \%$ (of water value) initially to $37 \%$ at end of the test. The crystal cracked after test completion.

** No. USV-24 cracked during test due to thermal shock (caused by malfunction of the sodium 10op) after two days of testing. After startup (three days later), the sensitivity reduced to about 19\% where it stayed for the remainder of the testing.

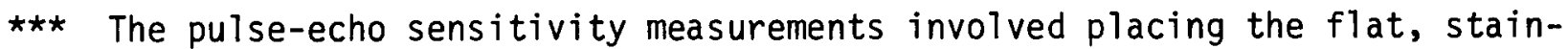
less steel reflector perpendicular to the beam at the nominal focal point of the transducer, and then measuring the amplitude of the first return echo. The applied pulse measured $200 \mathrm{~V}$ into 50 ohms. A variable inductor served to tune the transducer to maximum signal. 
- The sodium temperature ranged from $470^{\circ} \mathrm{F}$ to $500^{\circ} \mathrm{F}$ during the tests.

- The transducers were undamped, $5 \mathrm{MHz}$ units of 0.35-in. diameter PZT (lead-zirconate-titanate) active element with a 2-in. focal length in sodium.

Further experiments will be conducted with the transducers to determine sensitivity in static sodium after several weeks of storage in an inert atmosphere and to determine in-water sensitivity after completion of all planned tests. The results to date indicate that the newly developed transducer will be suitable for extended use at the projected FFTF temperature.

Transducer wetting in reactor-grade sodium has proven to be reliable and complete enough to assure the acquisition of good results. Fifteen of the eighteen transducers tested in sodium were wet by sodium well enough to obtain usable signals. Of the three transducers which did not wet, one had been initially immersed in relatively "dirty" sodium in a static pot. The two remaining transducers, one of 304 stainless steel and one of 1018 mild steel, had been thermally etched in a vacuum, but they did not have the gold passivation layer deposited on the face (see Transducer Fabrication section of this report); consequently, wetting could not be expected. These units served as controls to verify the necessity for gold passivation. Considerable simplification in the fabrication procedure would result if this layer could be eliminated. Thus, in summary, all but one of the gold-coated transducers wet properly in the liquid sodium.

At this stage in the transducer development, only undamped units (see Transducer Fabrication) have been used; these tend to "ring" and to produce a high noise level (particularly if poorly wetted). Figure 11 shows a signal from a typical focused (2-in. focal length in sodium) under-sodium viewing transducer. This signal results from a reflection off a flat stainless steel disc in sodium at $490^{\circ} \mathrm{F}$. The signal amplitude, about 1 volt peak-to-peak, is approximately $30 \%$ of that obtained in water under similar conditions. The 


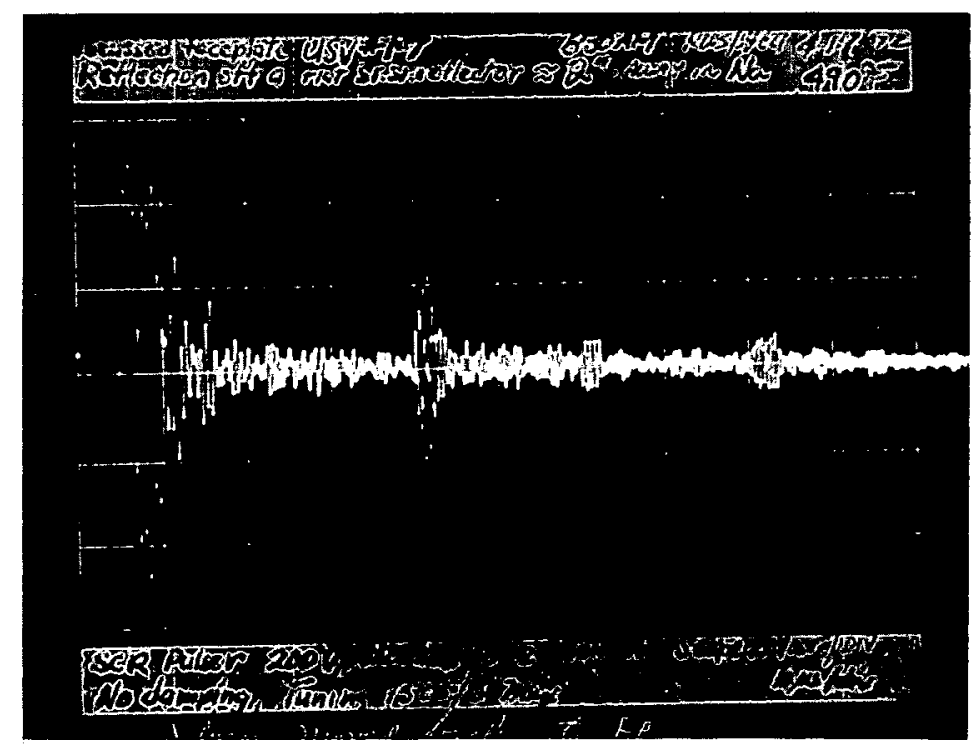

721854-1

Figure 11. Uitrasonic Signal Reflected off a Flat Stainless Steel Target in $490^{\circ} \mathrm{F}$ Sodium 
transducer noise level, not a particular problem with this unit, has been significantly higher with some of the units tested. Reduction of the noise level can be accomplished by:

- Damping the active element.

- Using a different type of active element (such as lead metaniobate).

- Improving the wetting procedure.

- Moving the focal point away from the transducer.

Some of the earlier transducers failed during in-sodium testing. These early failures at high temperature resulted from deterioration of the epoxy used to bond the active element to the metal lens and from oxidation of the back electrode on the active element. Improved performance resulted from development of a metal bonding technique to fasten the active element to the lens and from the use of platinum or gold for the back electrode. No more failures of this type have occurred.

\section{TRA!ISDUCER WETTING PROCEDURES}

To assure proper performance, the face of the ultrasonic transducer used for under-sodium imaging must be quickly wet by sodium at temperatures of 450 to $500^{\circ} \mathrm{F}$. Almost no ultrasound can be transmitted through an unwet interface, and virtually all will be reflected by what is essentially equivalent to a "gas layer" between the transducer face and the sodium. Certainly for FFTF use, the wetting should be rapid (less than one hour) to avoid long delays before imaging can begin.

Information in the literature about the wetting of metals by liquid sodium provides little insight to the problems. Apparently, no one has developed an explanatory "model" regarding the behavior of liquid sodium with stainless stee1. However, from the literature, from discussions with other HEDL experimenters, and from our experience, the following general conclusions can be 
stated:

- The wetting of stainless steel by liquid sodium has a time-temperature relationship; above $800^{\circ} \mathrm{F}$, wetting will be rapid and complete, while below $800^{\circ} \mathrm{F}$, wetting takes a progressively longer time (see Figure 12 ); at $450^{\circ} \mathrm{F}$, untreated stainless steel can take weeks to wet.

- The wetting time and the degree of wetting will be strongly influenced by the amount of oxygen dissolved in the sodium; i.e., wetting appears to be generally more complete and rapid in sodium containing relatively little oxygen $\left(<5 \mathrm{ppm} \mathrm{O}_{2}\right)$; however, no universal agreement exists on this, and the difficulty in measuring the oxygen content presents added problems.

- The wetting time and the degree of wetting will be strongly influenced by the surface condition of the stainless steel; proper conditioning of the surface can substantially reduce the wetting time.

A technique to promote more rapid wetting at temperatures of 400 to $500^{\circ} \mathrm{F}$ has been developed by W. L. Kelly and R. W. Smith ${ }^{(4)}$. Basically, this technique involves cleaning the transducer faceplate in a relatively high vacuum $\left(10^{-6}\right.$ torr or better) by a thermal etching process, and then depositing a layer of gold on the faceplate to keep it clean and prevent oxidation. In sodium, the gold rapidly dissolves away, thereby exposing the clean transducer face to the sodium (the Transducer Fabrication section provides further details on this).

Using the described techniques, signal levels as high as $50 \%$ of the water pulse-echo signals have been achieved in $450^{\circ} \mathrm{F}$ sodium. In reactor-grade sodium, as found in a purified 10op, the obtained results have been between $10 \%$ and $50 \%$ of the in-water, pulse-echo sensitivity, and the wetting time has generally been a few minutes or less. 


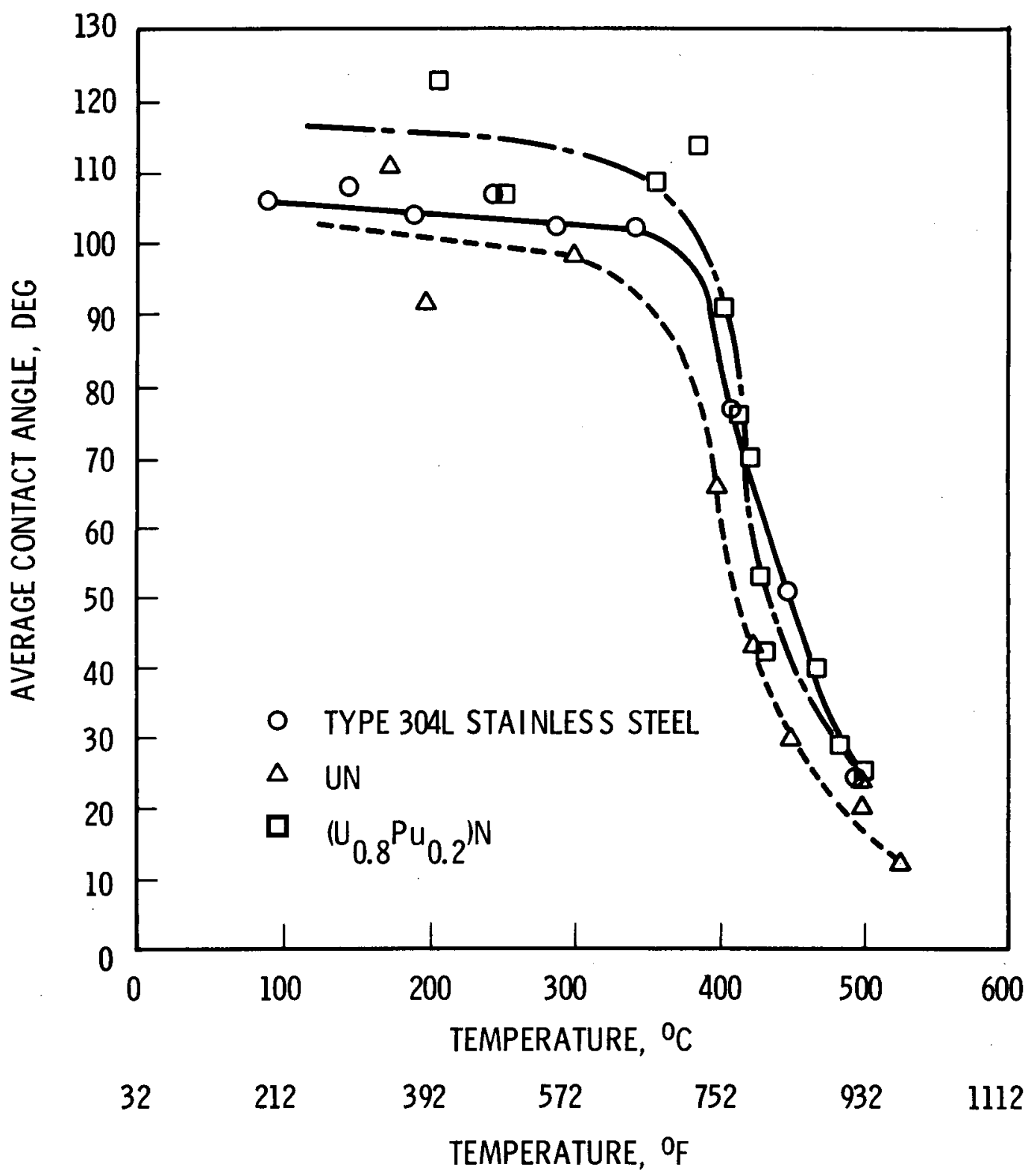

Figure 12. *Temperature Effects of Sodium Wetting on Various Materials

* See Ref. 5 
Transducer wetting will be poor in static liquid sodium which has been exposed to the usual "inert" atmosphere for a time, since sodium absorbs oxygen, even from a relatively inert atmosphere. The rate of absorption appears to be accelerated by water vapor in the atmosphere over the sodium and by stirring or agitation of the surface (5). Thus, testing and imaging in static sodium poses a problem in that the oxygen content of the sodium will continually increase, thus affecting transducer wetting and the validity of the test results.

\section{TRANSDUCER FABRICATION}

At the present stage of development, each experimental transducer comprises an undamped piezoelectric active element encased in stainless steel for protection against the sodium. Figure 13 shows the basic configuration. The active element, typically lead-zirconate lead-titanate ceramic (some lead-metaniobate active elements have been used), is banded to the back side of the lens (304 stainless steel). Copper-clad metal "v" seals* prevent entry of the liquid sodium. A spring-loaded electrical contactor makes contact to the back electrode of the crystal, and a polyimide (a high-temperature, radiationresistant plastic) insulator isolates the contactor from the housing. A spherically curved lens machined into the transducer face focuses the ultrasound at a point $F$ determined by

$$
F=R\left(\frac{n}{n-1}\right) \text {, }
$$

where $R$ is the radius of curvature of the surface, and $n$ the index of refraction for sound between the lens material and sodium. The following equation gives the index of refraction:

$$
n=\frac{v_{1}}{v_{2}},
$$

with $v_{1}$ and $v_{2}$ being the sound velocities in the lens and in sodium, respectively.

Most of the transducers fabricated to date have been focused $5 \mathrm{MHz}$ units

\footnotetext{
* Parker Seal Co., Culver City, Calif.
} 




Figure 13. Under-Sodium Viewing Transducer Assembly -USV Series 
having an active element diameter of $0.350 \mathrm{in}$. and having a 2 -in. focal point in sodium (some flat-faced units have also been fabricated and tested). The 2-in. focused units were designed to permit imaging and testing in a small volume of sodium; however, this is not the optimum configuration for imaging in a practical situation.

A newer transducer design uses a Swagelok * fitting to seal the transducer. This design results in a smaller diameter transducer and an improved, more convenient seal. Testing of these units has thus far been limited to static sodium pots in which they operated satisfactorily. Figure 14 shows the transducer assemblies.

A key factor in the fabrication of transducers for use in sodium is the bond fastening the active element to the lens that protects the active element from the sodium and focuses the ultrasound. The bonding material presently being used is a lead alloy solder $(1.5 \% \mathrm{Ag} / 5 \% \mathrm{Sn} / 93.5 \% \mathrm{~Pb})$ which melts at about $560^{\circ} \mathrm{F}$. This bond must withstand the temperature and radiation levels projected for FFTF shutdown and must provide proper acoustic coupling between the active element and the lens. Further, the bond must have adequate ductility to accommodate the large difference in thermal expansion between the active element and the lens (about 6 to 1 ). In addition, the bonding operation must be compatible with the fabrication technique used to promote rapid wetting of the transducer. The bonding operation must be done in a vacuum to prevent re-oxidation of the transducer face; thus, soldering flux cannot be used.

Preparation of the active elements involves removal of the normally supplied fired-on silver electrodes: these dissolve in solder and the electrode-to-crystal bond is not very good. A two-micron thick copper elctrode is then sputtered on the positive (or lens) side of the plate and a two-micron thick platinum electrode is sputtered on the negative side. This procedure results in well-bonded electrodes: the solder bonding alloy readily wets the copper, and the platinum electrode does not oxidize away. It sometimes becomes

* Crawford Fitting Co., Cleveland, Ohio 


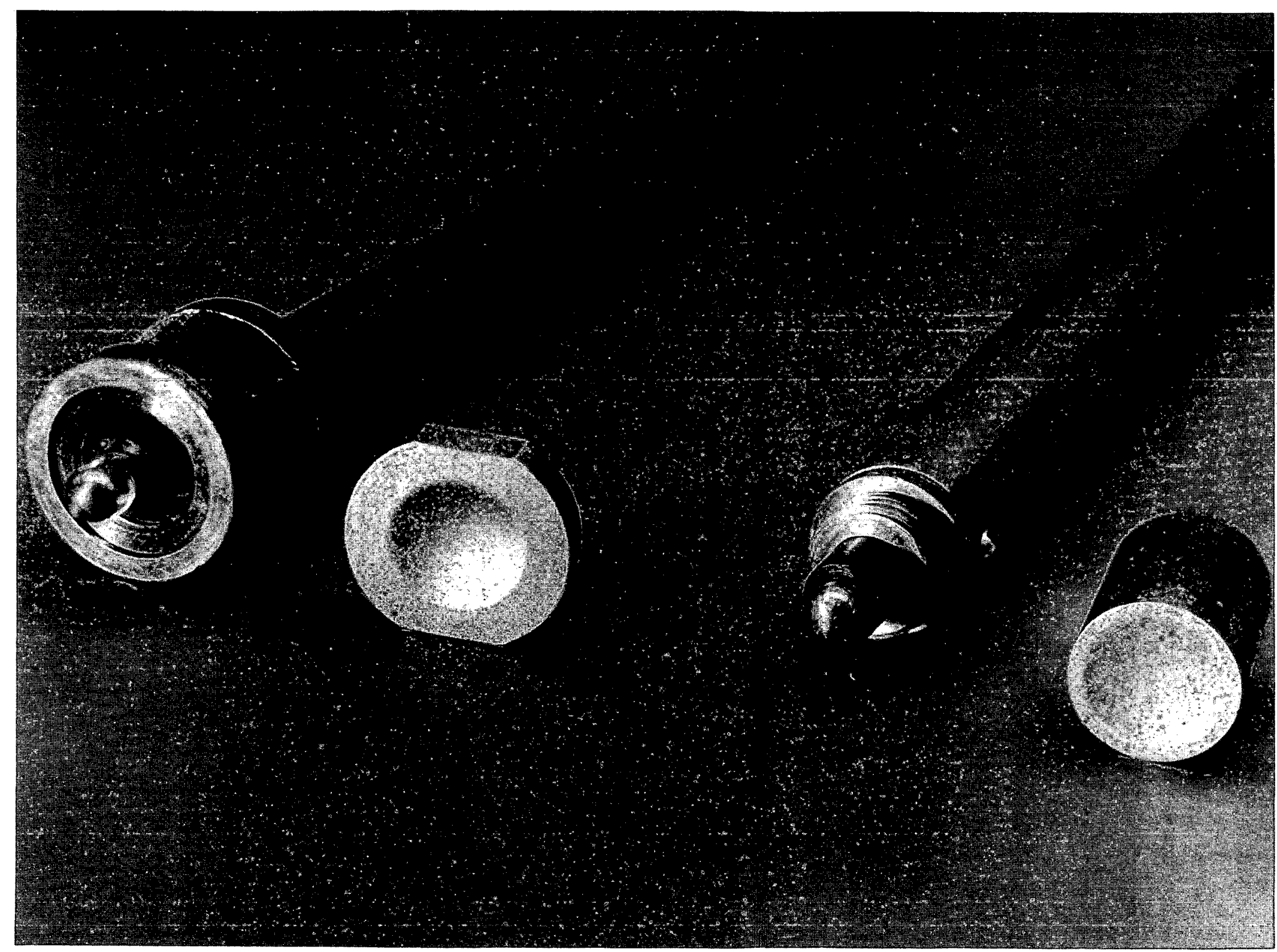

Figure 14. Photos of Transducer Assemblies

721808-2

0 
necessary to repole the ceramic elements after the sputtering operations.

The back surface of the stainless steel lens must be prepared to induce the bonding alloy to wet the lens. Deposition of a copper bonding layer on the back side of the lens precedes the bonding of the active element. Vapor deposition of the copper coating starts with the transducer lens at approximately $950^{\circ} \mathrm{C}$ and continues as the lens cools. This treatment diffuses part of the copper into the lens and results in a well-bonded copper layer readily wet by the bonding alloy; attempts to vapor-deposit this layer onto a cold lens resulted in poor bonding of the copper coating.

The basic procedure involves the simultaneous deposition of the copper bonding layer and the gold passivation layer onto the transducer lens (faceplate) as it cools down from the thermal etch cycle. The gold deposition starts slightly before termination of heating of the faceplate in order to passivate the transducer face as quickly as possible. The deposit consists of a one micron layer of both copper and gold on the faceplate, but some will be lost by diffusion and by re-evaporation.

The front face of the transducer lens is cleaned by a thermal etching technique. During the thermal etch cycle, induction heating brings the lens to about $1150^{\circ} \mathrm{C}$ in a vacuum typically better than $10^{-6}$ torr. After 30 minutes at $1150^{\circ} \mathrm{C}$, the copper and gold depositions start and heating stops. Figure 15 depicts the arrangement used to process the faceplates.

Figure 16 shows the apparatus used with an inductively heated "hot plate" to bond the active element to the lens. This operation takes place in a vacuum chamber to avoid contaminating or oxidizing the faceplate. Good mechanical contact must be achieved to insure good thermal conductivity; thus, spring pressure clamps the faceplate against the heater plate, and a screw clamps the active element into the faceplate. Heating the assembly to about $610^{\circ} \mathrm{F}$ over a period of about 15 minutes melts the bonding alloy; and at this point, release of pressure holding the element into the faceplate allows the active element to 


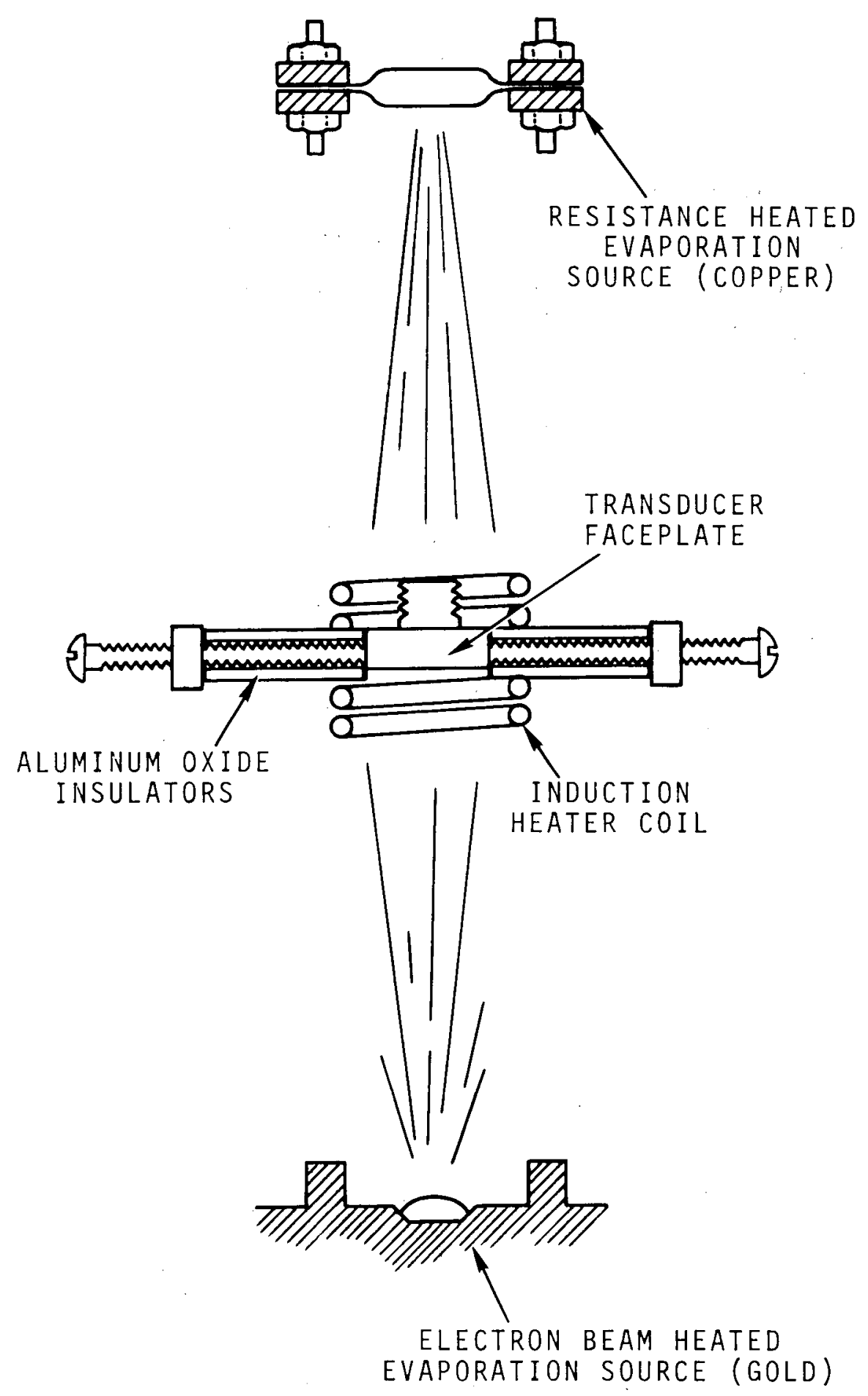

Figure 15. Thermal Etching/Deposition Assembly 


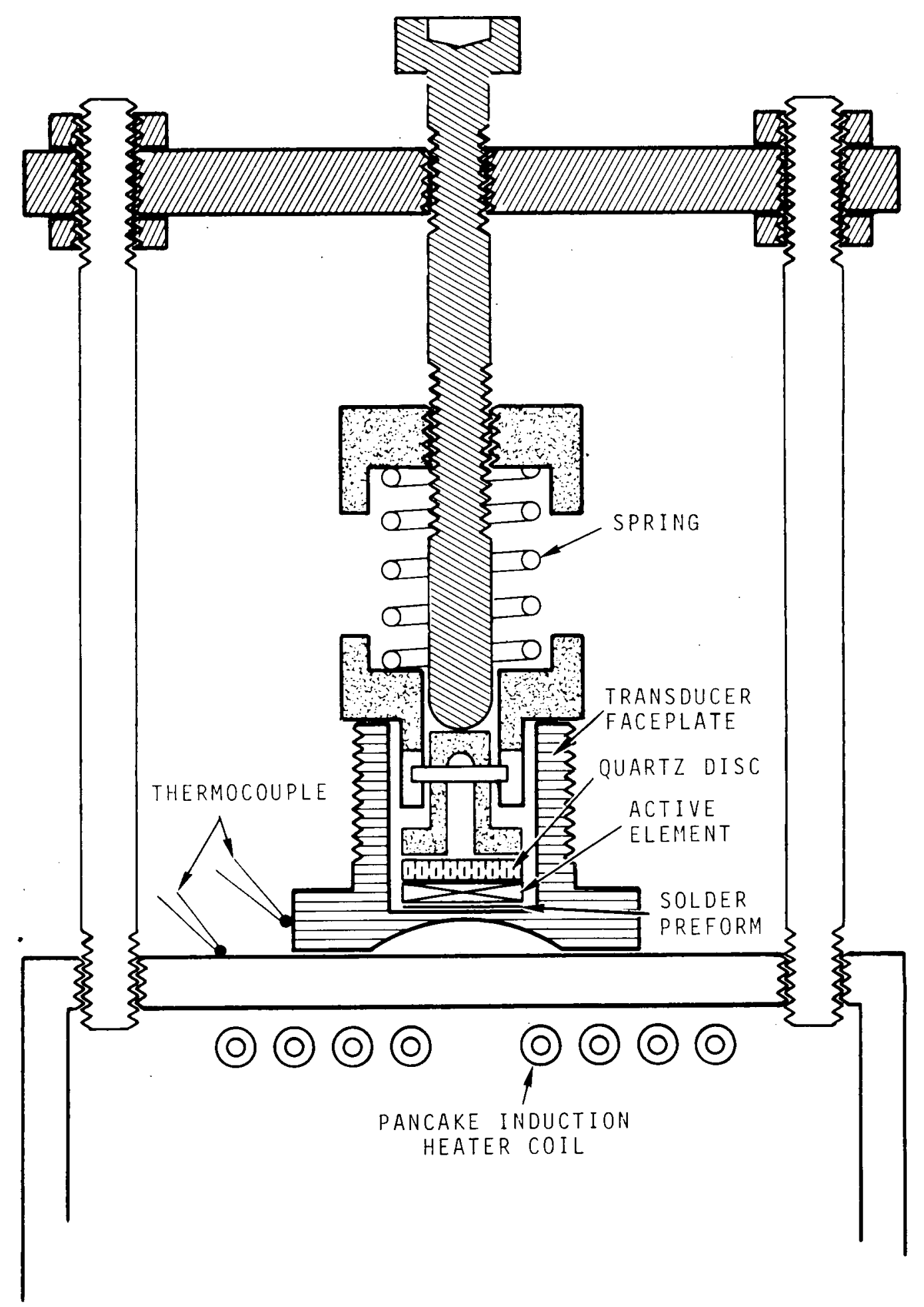

Figure 16. Bonding Assembly 
"float" on the molten bonding alloy. Slow cooling of the faceplate precedes removal from the vacuum chamber.

\section{ACKNOWLEDGEMENTS}

The authors express appreciation to F. L. Becker and R. L. Trantow for their work in the design of the ISO-SCAN system used for our initial scanning; to $W$. L. Kelly for his effort in pursuing the transducer wetting problem; to C. L. Christensen and G. E. Adamson for their technical assistance in the laboratory; and to E. R. Wood for his assistance during the sodium tests. 


\section{$X . \quad$ REFERENCES}

L. J. R. Fothergill and I. D. Macleod, IEEE Conference Proceedings, No. 16, Conference on Industrial Ultrasonics at Loughborough University, September, 1969.

2. C. C. Scott and Shuy-Pan Ying, "Development of the Under-Sodium Ultrasonic Scanner", APDA-210, October, 1967.

3. F. L. Becker and R. L. Trantow, Patent Disclosure ARW-71-14, "A System For Ultrasonic Isometric Imaging", August 30, 1971.

4. W. L. Kelly and R. W. Smith. Private Communication.

5. W. H. Caplinger, Private Communication. 


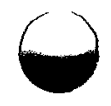

APPENDIX A

SCHEMATIC DIAGRAMS 


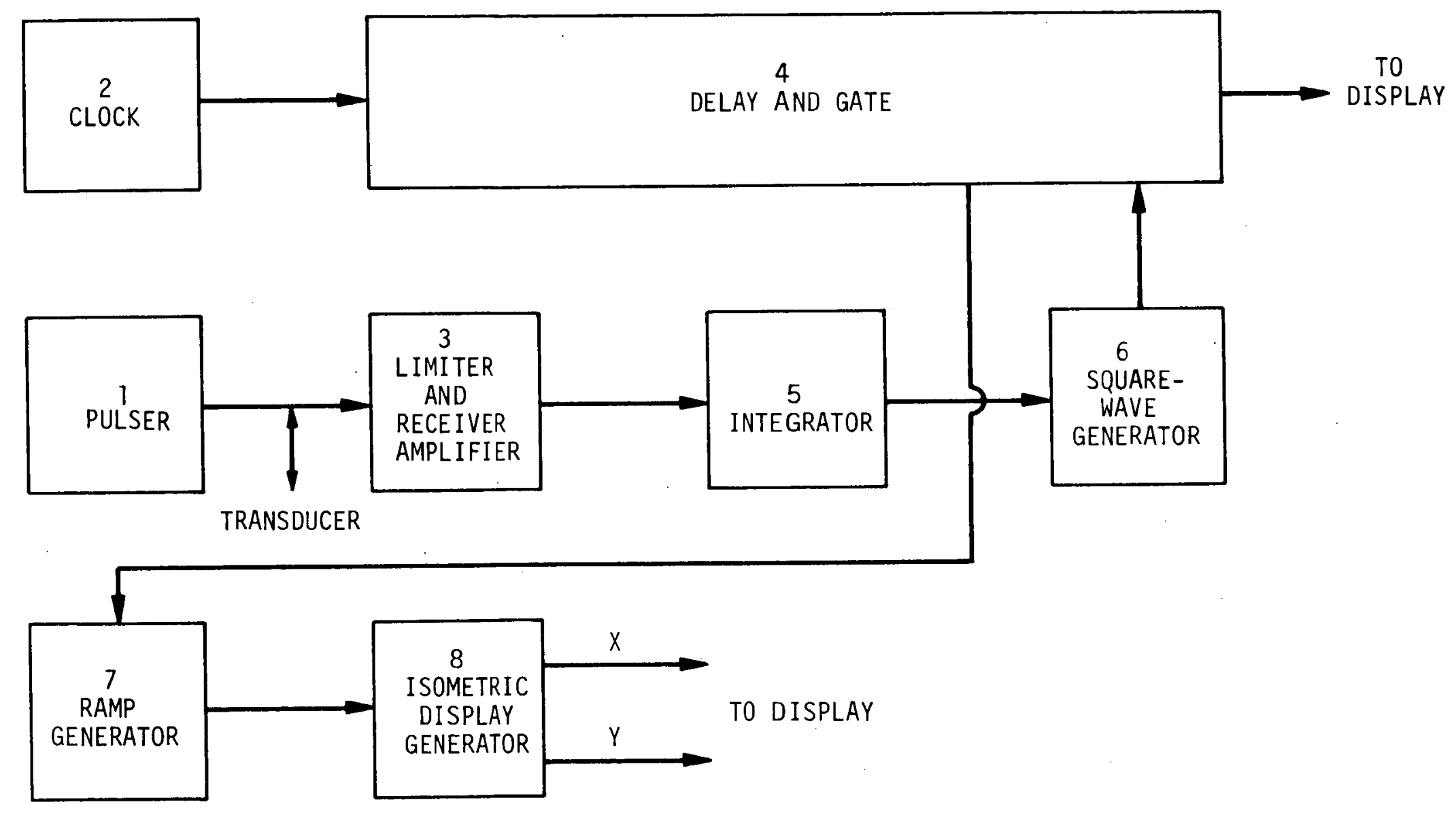

NOTE: NUMBERS REFER TO SCHEMATICS IN THIS APPENDIX.

No. $7207-18.10$

Figure A-1. Isometric System Block Diagram. 


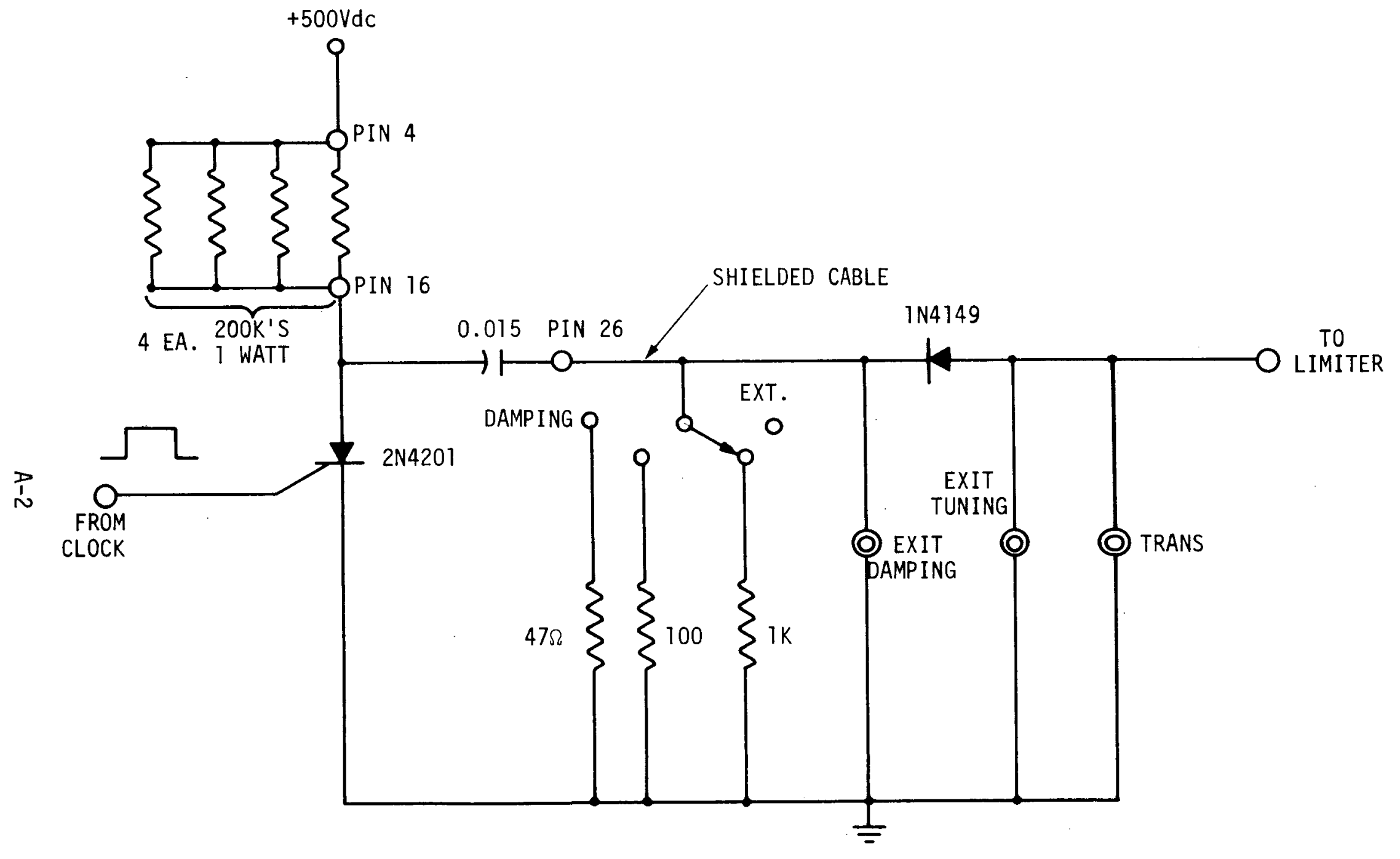

№. 7207-18.4

Figure A-2. Pulser Schematic 


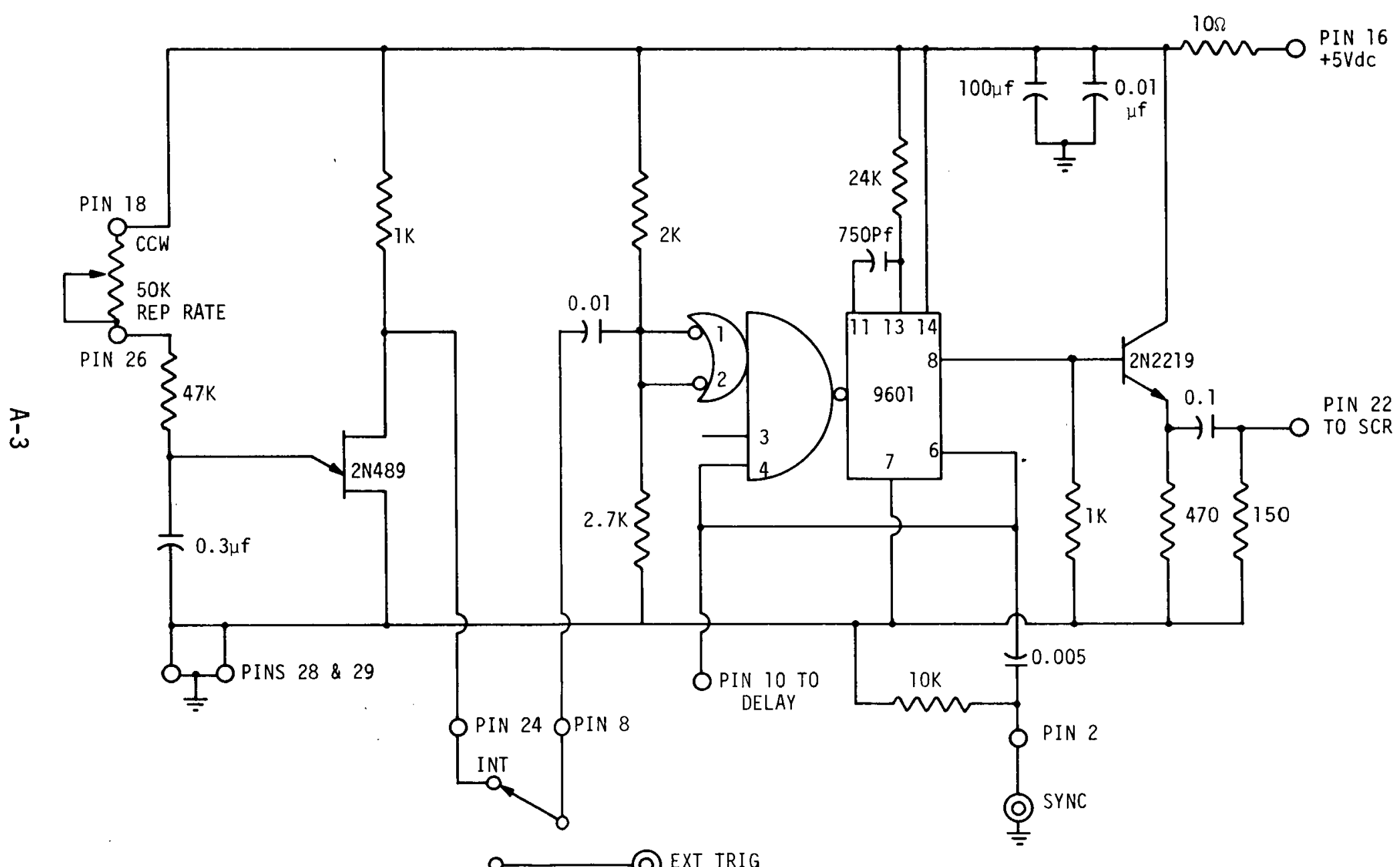

No. $7207-18.6$

Figure A-3. Clock Schematic. 


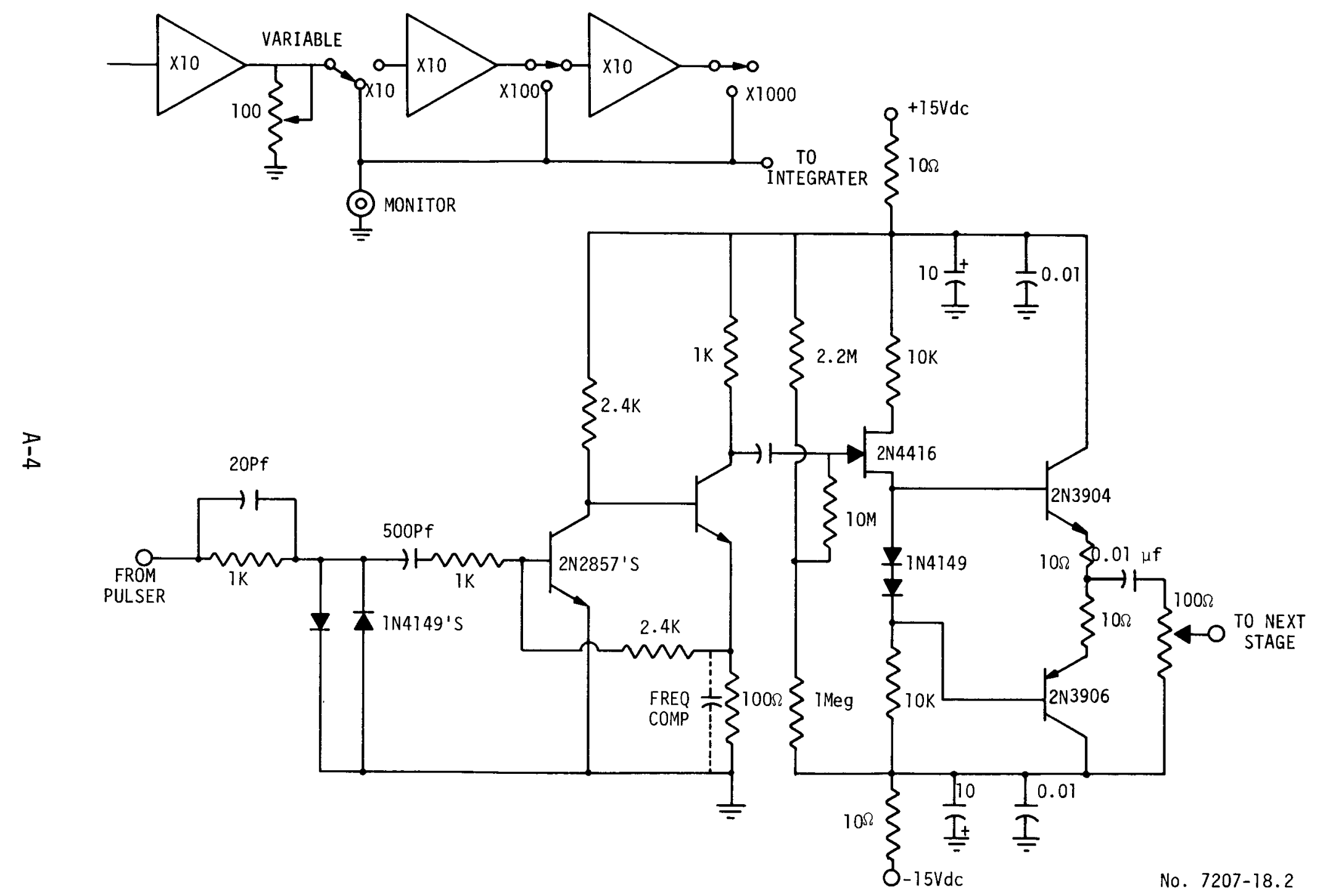

Figure A-4. Amplifier Schematic (First Stage Only) 


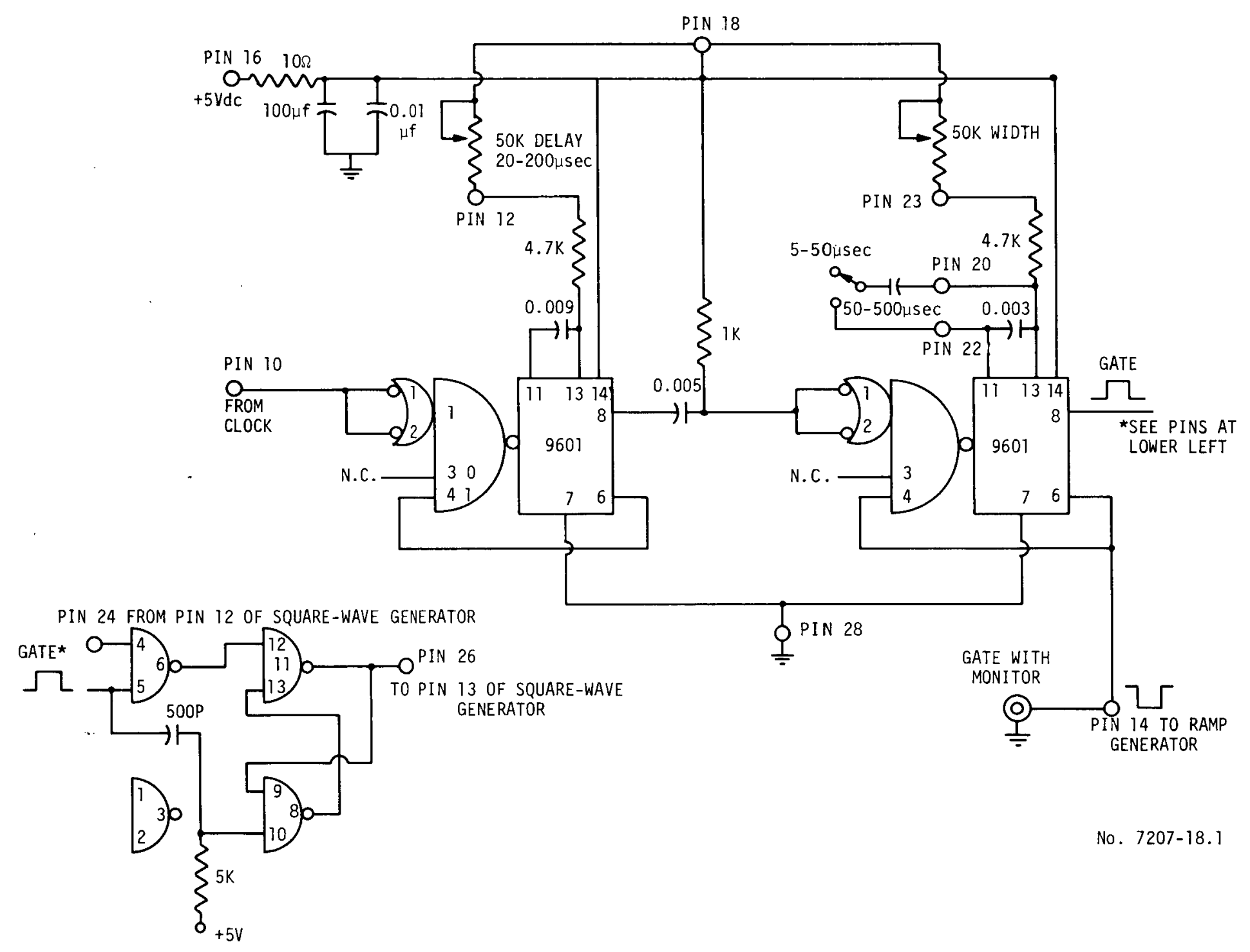

Figure A-5. Delay, Gate Schematics. 


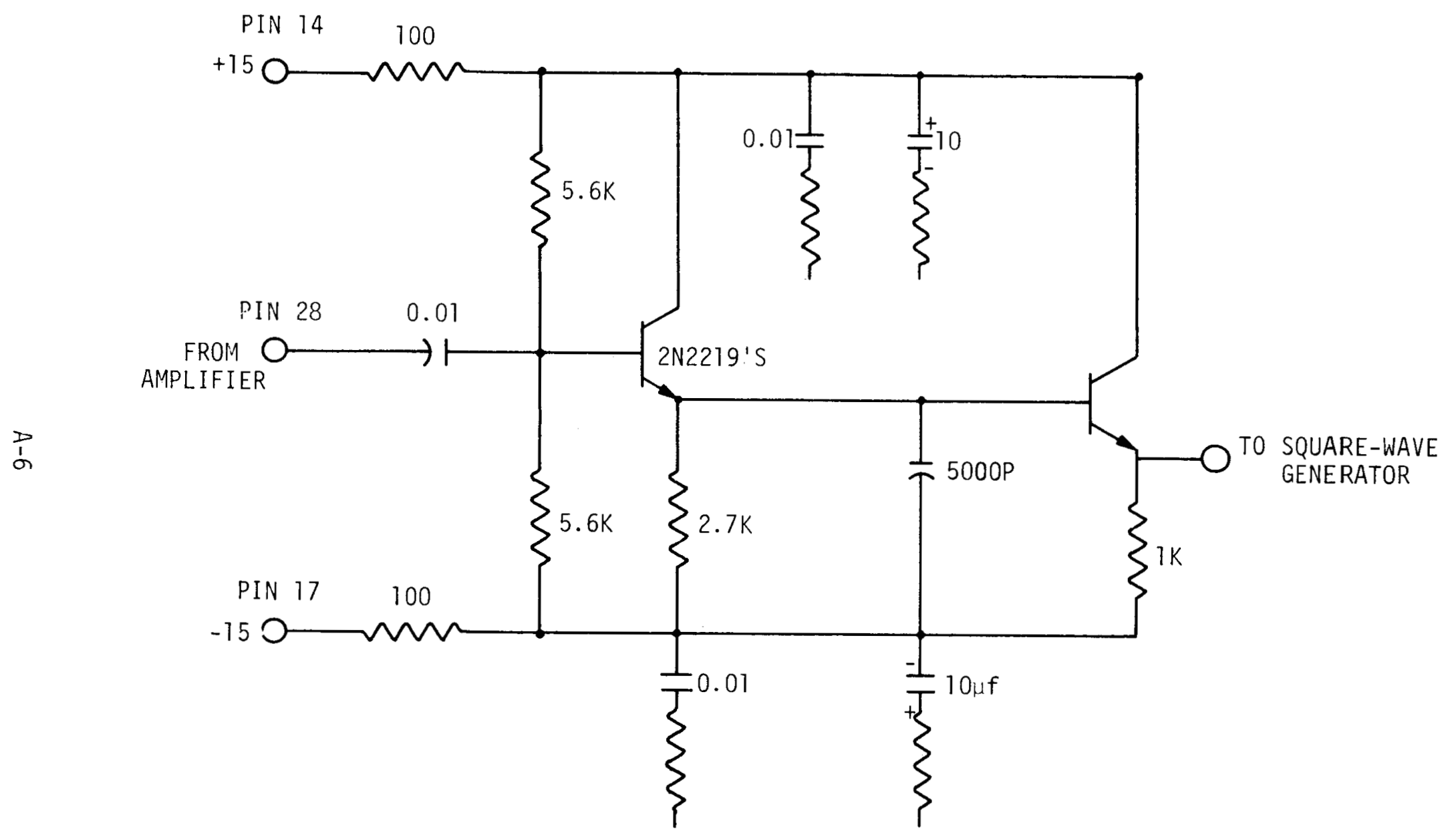

No. 7207-18.7

Figure A-6. Integrator Schematic. 




Figure A-7. Square-Wave Generator Schematic. 


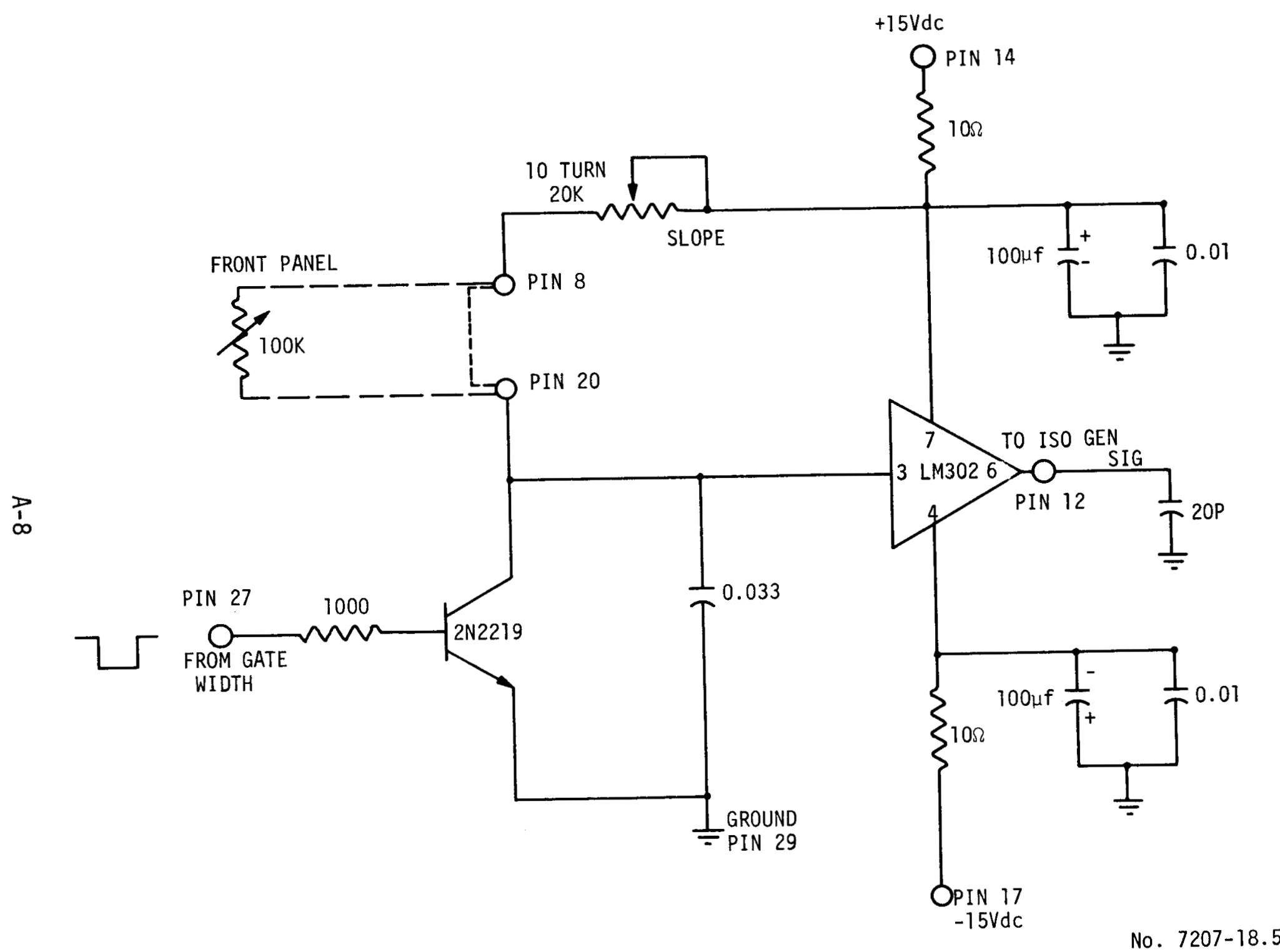

Figure A-8. Ramp Generator Schematic

O 


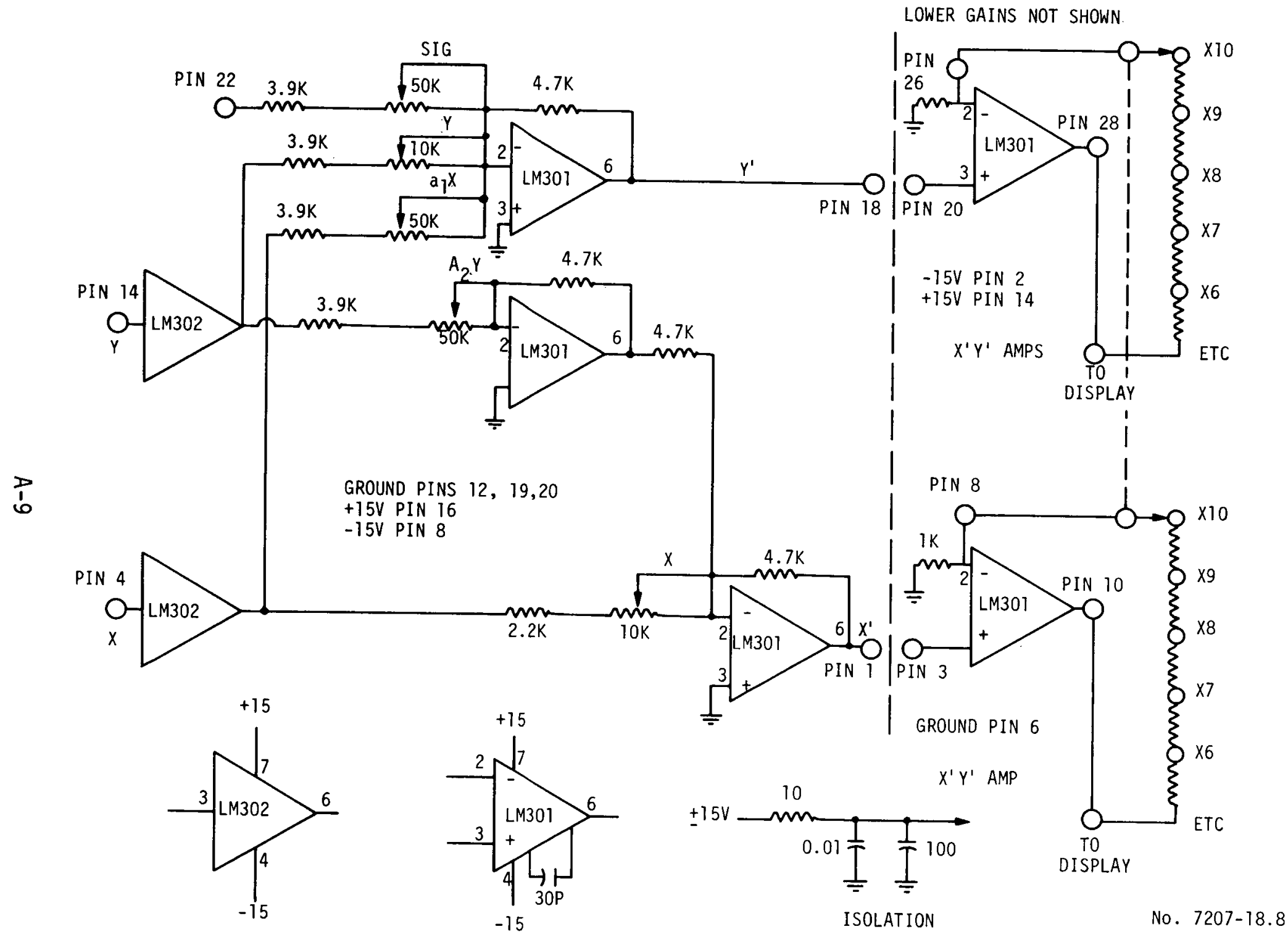

Figure A-9. Isometric Display Generator Schematic. 
DISTRIBUTION

iNo. of

Cooies

OFFSITE

28 AEC Div. of Reactor Dev. and Tec.

Director, RDT

Asst. Dir for Nuclear Safety

Analys is \& Evaluation Br, RDT:NS

Asst. Dir for Plant Engr., RDT

Facilities $\mathrm{Br}$, RDT:PE

Components $\mathrm{Br}$, RDT:PE

Instrument \& Control $\mathrm{Br}$, RDT:PE

Liquid Metal Systems $B r$, RDT:PE

Asst. Dir for Program Ana?, RDT

Asst. Dir for Project Mgmt, RDT

Liquid Metals Projects Br, Rdt:PM

FFTF Project Manager, RDT:PIM (3)

Asst. Dir for Reactor Engrg, RDT

Control Mechanisms Br, ROT:RE

Core Design $\mathrm{Br}$, RDT:RE

Core Design Br, RDT:RE (2)

Fuel Engineering Br, RDT:RE

Fuel Handling $\mathrm{B} r$, RDT:RE

Reactor Vessels Br, RDT: RE

Coolant Chemistry Br, RDT:RT

Fuel Recycle Br, RDT:RT

Fuels \& Materials Br, RDT:RT

Reactor Physics Br, RDT:RT

Special Technology Br, RDT:RT

Asst. Dir for Engrg Standards: RDT

LMFBR Project Manager, RDT:PM

3 AEC Division of Reactor Licensing

Director (3)

2 AEC Division of Reactor Standards

Director (2)

1 AEC San Francisco Operations Office

Director, Reactor Division

5 AEC Site Representatives

Argonne National Laboratory - ID

Argonne National Laboratory - AR

Atomics International

General Electric Company

Westinghouse Electric Corporation

1 Atomics International

Westinghouse Field Manager

J. S. Theilacker

$?$ Bechtel Corporation

Project Admin., FFTF

J. J. Teachnor

15 Westinghouse Electric Corporation

Advanced Reactor Division

ATTENTION: L. Wickas

Nuclear Energy Systems

M. Vasilakis (Library)
No. of

Copies

2 TIC

1 AEC Idaho Operations Office

Nuclear Technology Division

C. W. Bills, Director

Aerojet Manufacturing Company

S. G. Harbison

3 Argonne Nationa 1 Laboratory

LMFBR Program Office

R. A. Jaross

A. Trave11i

1 Atomic Power Develooment As soc.

Document Librarian

11 Atomics International

FFTF Program Office (5)

D. J. Cockram (5)

FBR Project

Definition Phase

W. T. Morgan

1 Babcock \& Wilcox Co.

Atomic Energy Division

S. H. Esleeck

1 Combustion Engineering (Conn.)

1000 Mule Follow-on Study

W. P. Staker, Project Manager

1 Combustion Engineering (Tenn)

Mrs. Nell Holder, Librarian

4 General Electric Co. (Sunnyvale)

Breeder Reactor Department

Technical Library (3)

Demonstration Plant Program

L. F. Fidrych

2 Gulf General Atomic Inc.

General Atomic Division

R. H. Simon, Mgr. Proj. Dept. GCFR Program

1 Allied Chemical Corporation

J. A. Buckham

1 Liquid Metal Engineering Center

R. W. Dickinson

2 Liquid Metal Information Center

A. E. Miller 
No. of

Copies

2 Oak Ridge National Laboratory

W. O. Harms

P. Partiarca

1 Gulf United Nuclear Fuels Corporation

Research and Engrg Center Library

R. F. DeAngel is

\section{ONSITE}

No. of

Copies

2 AEC Richland Operations Office

J. H. Sako

J. M. Shivley

1 RDT/PNP

F. R. Standerfer

101 Westinghouse Hanford Company
G. J. Alkire
T. 0. Harves
J. B. Henshall
H. J. Anderson
D. L. Ballard
F. L. Becker
R. A. Bennett
T. R. Billeter
D. P. Brown
R. L. Brown, Jr.
W. F. Carlson
R. J. Cash
T. T. Claudson
R. R. Cone
J. Connel1
C. K. Day
L. J. Defferding
L. E. Fort
D. C. Frick
D. Gray
R. S. Hammond
P. L. Hofmann
F. E. Holt
C. N. Jackson
J. N. Judy
W. C. Kinsel
H. T. Knight
F. J. Leitz
C. E. Linderoth
J. W. Mitchel 1
C. A. Munro
W. J. McShane
J. C. Noakes
R. N. Ord (20)
D. G. Ott
H. N. Pedersen
L. D. Philipp
N. S. Porter

W. E. Roake

G. J. Rogers

D. M. Romrell

C. B. Shaw

W. F. Sheely

A. L. Smith

R. W. Smith (20)

J. C. Spanner

W. G. Spear

J. L. Stringer

C. D. Swanson

R. L. Trantow

A. L. Trego

A. B. Webb

S. A. Weber

J. F. Wett

M. R. Wood

J. M. Yatabe

Document Control (5)

Tech Publications (2) 